\title{
A revision of Nazeris. VI. On the fauna of East Yunnan, China (Coleoptera: Staphylinidae: Paederinae)
}

\author{
With 75 figures and 3 maps
}

VOLKER ASSING ${ }^{1}$

${ }^{1}$ Gabelsbergerstraße 2, 30163 Hannover, Germany. - vassing.hann@t-online.de Published on 2014-12-15

\section{Summary}

A recent field trip to eastern Yunnan (Southwest China), a region from where only one species of Nazeris FAUVEL, 1873 had been known, yielded thirteen undescribed Nazeris species, eleven of which are described and illustrated: N. brevilobatus sp. n. (Dongchuan env.), N. virilis sp. n. (Wuding env.), N. constrictus sp. n. (Gejiu env.), N. claviger sp. n. (Gejiu env.), and N. discissus sp. n. (Pingbian env.) of the newly established N. brevilobatus group; N. lamellatus sp. n. (Pingbian env.) of the newly established N. lamellatus group; N. semifissus sp. n. (Pingbian env.) of the newly established N. semifissus group; N. fibulatus sp. n. (Kunming env.), N. bulbosus sp. n. (Kunming env.), N. clavilobatus sp. n. (Dongchuan env.), and N. conicus sp. n. (Xundian env.) of the N. cangicus group. Together with N. zhangi Watanabe \& XiaO, 1993, the latter three species form a distinct lineage within the N. cangicus group. Two species remain unnamed, as they are represented exclusively by females. The general distribution of the genus in Yunnan and the individual distributions of the newly described species are mapped. Nazeris now includes a total of 233 described species (plus seven subspecies), 118 of which have been recorded from mainland China. The fauna of Yunnan currently comprises 45 described species.

\section{Key words}

Coleoptera, Staphylinidae, Paederinae, Nazeris, Palaearctic region, China, Yunnan, taxonomy, new species, species groups, distribution maps, diversity.

\section{Zusammenfassung}

Eine im Sommer 2014 durchgeführte Exkursion im östlichen Yunnan (Südwest-China), einer Region, aus der bisher erst eine Art der Gattung Nazeris FAUVEL, 1873 bekannt war, erbrachte insgesamt dreizehn unbeschriebene NazerisArten, von denen elf beschrieben und abgebildet werden: N. brevilobatus sp. n. (Umgebung Dongchuan), N. virilis sp. n. (Umgebung Wuding), N. constrictus sp. n. (Umgebung Gejiu), N. claviger sp. n. (Umgebung Gejiu) und N. discissus sp. n. (Umgebung Pingbian) der neu begründeten N. brevilobatus-Gruppe; N. lamellatus sp. n. (Umgebung Pingbian) der neu begründeten N. lamellatus-Gruppe; N. semifissus sp. n. (Umgebung Pingbian) der neu begründeten N. semifissus-Gruppe; N. fibulatus sp. n. (Umgebung Kunming), N. bulbosus sp. n. (Umgebung Kunming), N. clavilobatus sp. n. (Umgebung Dongchuan) und N. conicus sp. n. (Umgebung Xundian) aus der N. cangicus-Gruppe. Zusammen mit N. zhangi Watanabe \& XIaO, 1993 bilden die drei letztgenannten Arten eine phylogenetische Linie innerhalb der N. cangicus-Gruppe. Zwei ausschließlich durch Weibchen vertretene Arten bleiben unbeschrieben. Die derzeit bekannte allgemeine Verbreitung der Gattung in Yunnan sowie die Lage der Fundorte der neubeschriebenen Arten werden anhand von Karten illustriert. Nazeris enthält nunmehr insgesamt 233 beschriebene Arten (mit sieben Unterarten), von denen 118 Arten in China (ohne Taiwan) vorkommen. Aus Yunnan sind derzeit 45 beschriebene Arten bekannt. 


\section{Introduction}

The speciose Palaearctic genus Nazeris Fauvel, 1873 previously included as many as 222 named species and seven subspecies, all of them micropterous and with more or less restricted distributions. Nearly half of these species (107 species) have been recorded from China, 48 from the Himalaya, 25 (plus six subspecies) from Japan, 21 (plus one subspecies) from Taiwan, seven from North Vietnam, two from northern Thailand, and one from South Korea. The West Palaearctic Nazeris fauna (eleven species) is far less diverse than that of the East Palaearctic region. In China, the diversity is greatest in Yunnan (34 species) and Sichuan (22 species) (Assing 2014a, b). The previously known distribution of the genus in Yunnan is remarkably biased: with one exception, $N$. zhangi WatanabE \& XIAO, 1993 from the environs of Kunming, Nazeris had been reported exclusively from western Yunnan (Assing 2013). The present study is based on Nazeris material collected during a field trip to eastern Yunnan conducted by Michael Schülke (Berlin) and the author in summer 2014. This material is composed of as many as thirteen undescribed species. Two of them, however, are represented only by females and consequently remain unnamed.

\section{Material and methods}

The material treated in this study is deposited in the following public institution and private collections:

MNHUB Museum für Naturkunde der HumboldtUniversität Berlin (J. Frisch)

cAss author's private collection

cSch private collection Michael Schülke, Berlin

The morphological studies were conducted using a Stemi SV 11 microscope (Zeiss Germany) and a Jenalab compound microscope (Carl Zeiss Jena). The images of the forebodies and the aedeagi in dry preparation were created using a photographing device constructed by Arved Lompe (Nienburg) and CombineZ software. A digital camera (Nikon Coolpix 995) was used for the remaining photographs. The maps were created using MapCreator 2.0 (primap) software.

Body length was measured from the anterior margin of the mandibles (in resting position) to the abdominal apex, the length of the forebody from the anterior margin of the mandibles to the posterior margin of the elytra, head length from the anterior margin of the frons to the posterior constriction of the head, elytral length at the suture from the apex of the scutellum to the posterior margin of the elytra (at the suture), and the length of the aedeagus from the apex of the ventral process to the base of the aedeagal capsule. The "parameral" side (i.e., the side where the sperm duct enters) is referred to as the ventral, the opposite side as the dorsal aspect.

\section{Results and discussion}

\subsection{Diversity, biogeography, and natural history}

Including the new taxa described in this article, Nazeris now includes a total of 233 described species (plus seven subspecies), approximately half of which (118 species) have been recorded from mainland China alone. With 45 described species now known from Yunnan, this province hosts more than twice as many species as Sichuan and nearly $40 \%$ of all the species recorded from China. Yet, the true diversity of Nazeris in Yunnan is most likely significantly greater. All the species of the genus are micropterous and, consequently, have more or less restricted distributions. Except for some mountain ranges in the west, most regions in Yunnan have not been investigated thoroughly or have not been sampled at all in habitats and with methods suitable for collecting Nazeris. There are some obvious distribution gaps particularly in the north and the northeast, in the south and southwest, and in the region roughly between Wuding and Dali (see Map 1). The recent field trip to eastern Yunnan, from where only a single species had been reported previously, yielded new species in nearly all the regions examined and as many as three undescribed species each were discovered in the immediate vicinity of Gejiu and Pingbian. Therefore, it would not be surprising if the actual Nazeris fauna of Yunnan comprised up to a hundred species or even more.

The material from eastern Yunnan was collected by sifting leaf litter, roots of herbs, and moss in various forest and shrub habitats at a wide range of altitudes (1500-2620 m), with the majority of records between 1900 and $2400 \mathrm{~m}$. These figures, however, may reflect a bias and not potentially suitable altitude ranges for Nazeris. Higher elevations are difficult to access in the region and forest habitats at lower and intermediate elevations have largely been replaced with arable land. Accordingly, the lowest locality where Nazeris was found $(1500 \mathrm{~m})$ is situated in the environs of Pingbian, where semi-natural forests can still be found also at intermediate elevations.

\subsection{Species groups}

Primarily based on the male sexual characters, the species recorded from eastern Yunnan belong to four species groups.

The $N$. brevilobatus group includes six species ( $N$. brevilobatus, N. virilis, N. constrictus, N. claviger, N. discissus, one unnamed species), whose monophyly is constituted by several evident synapomorphies. The male sternite VII (e.g., Figs 2, 9) is distinctly modified (posterior margin with more or less pronounced median concavity with a pair of clusters of long dark setae) and the aedeagus (e.g., Figs 5-6, 12-13, 18-19) is of derived morphology (ventral process conspicuously long and apico-ventrally 


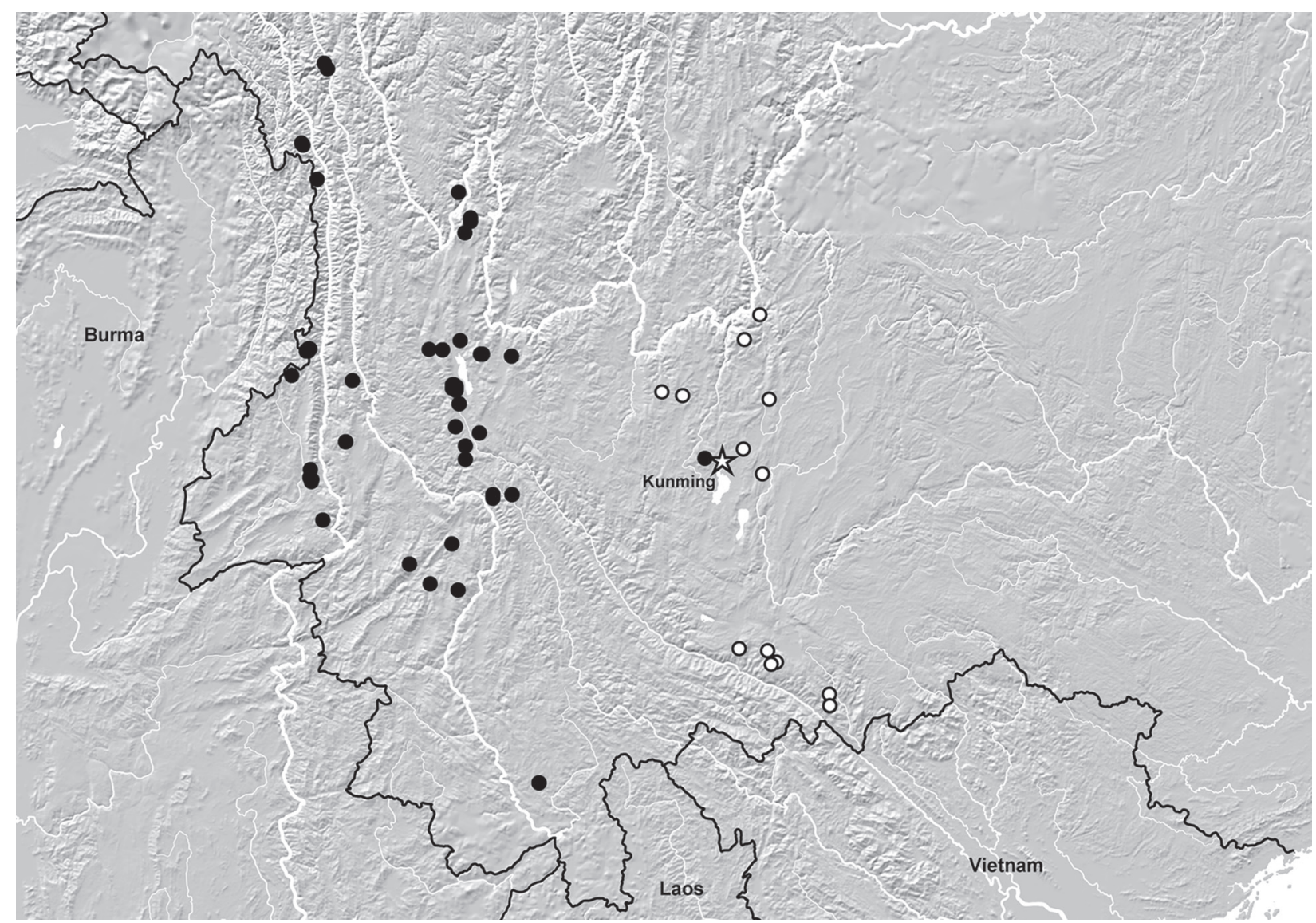

Map 1: Distribution of previously described (black circles) and newly described species (white circles) of Nazeris in Yunnan (white star: Kunming).

deeply divided; dorso-lateral apophyses remarkably short, in most species not even reaching middle of ventral process). In addition, the species of this group share the following characters: body of moderate to moderately large size and of black coloration; punctation of head shallow and not very coarse; elytral punctation defined and as coarse as that of pronotum (e.g., Figs 1,8); punctation of abdominal tergites III-VII very dense; posterior margin of tergite VIII strongly convex; male sternite VIII with moderately to strongly convex anterior margin and with rather deep, more or less V-shaped, and anteriorly very acute posterior excision (e.g., Figs 4, 11, 17); dorsolateral apophyses of the aedeagus weakly to moderately sclerotized and apically distinctly to strongly dilated. Species belonging to the N. brevilobatus group have been recorded only from eastern Yunnan, from the environs of Dongchuan in the north to Pingbian in the south (Map 2). The N.lamellatus group includes two species, one from Vietnam (N. odzisan Watanabe, 1996) and one (N. lamellatus) from southeastern Yunnan, both of which share the following evident synapomorphies: posterior margin of male sternite VII with a small, but distinct median excision (Fig. 35); male sternite VIII with a narrow posterior excision (Fig. 36); aedeagus with a very weakly sclerotized ventral process and with conspicuously short and weakly sclerotized dorsolateral apophyses (Figs 37-38).
The N. semifissus group is represented only by a single species from southeastern Yunnan, N. semifissus. It is characterized by the following clearly apomorphic characters: male sternite VII with a very large posterior excision furnished with a pair of clusters of long black setae directed mediad (Fig. 42); sternite VIII with conspicuously deep and narrow posterior incision reaching middle of sternite (Fig. 43).

The remaining five species belong to the $N$. cangicus group (see Assing 2013), which previously comprised numerous species from western Yunnan. The representatives of this group from eastern Yunnan clearly belong to two lineages, one of which includes only N. fibulatus from the environs of Kunming. The male sexual characters of $N$. fibulatus are most similar to those of some species recorded from western Yunnan. Nazeris zhangi Watanabe \& Xiao, 1993, N. bulbosus, N. clavilobatus, and $N$. conicus form a distinct lineage distributed in the environs, and in the region to the north, of Kunming (Map 3) and characterized particularly by the morphology of the dorso-lateral apophyses of the aedeagus (stout, heavily sclerotized, strongly curved in ventral view, and apically more or less clubbed) (Figs 55-58, 63-66, 72-75). These four species additionally share the following characters: body of relatively small size; pronotum with very coarse and regularly distributed punctation (much coarser than that of elytra), without 


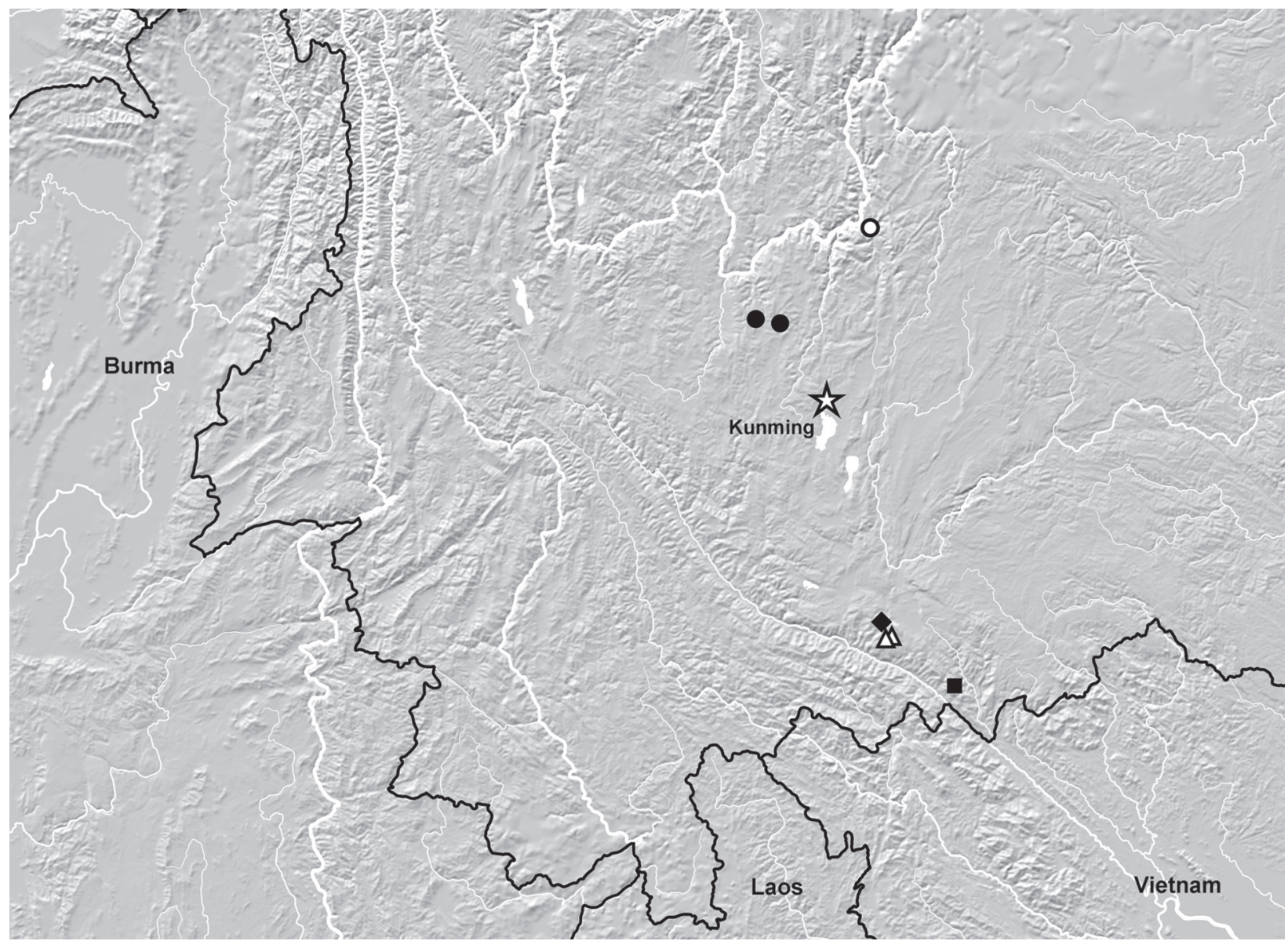

Map 2: Distribution of the named species of Nazeris brevilobatus group in eastern Yunnan: N. brevilobatus sp. n. (white circle); N. virilis sp. n. (black circles); N. claviger sp. n. (black diamond); N. constrictus sp. n. (white triangles), N. discissus sp. n. (black square).

lateral callosities (e.g., Figs 59, 68); posterior margin of tergite VII with rudiment of a palisade fringe; male sternite VII with sparse unmodified pubescence and only moderately transverse (e.g., Figs 61, 69); male sternite VIII more or less distinctly transverse, with moderately deep and rather wide posterior excision, otherwise unmodified (e.g., Figs 62, 70-71); aedeagus with short ventral process.

\subsection{Descriptions of new species}

\section{Nazeris brevilobatus sp. $\mathrm{n}$.}

(Figs 1-7, Map 2)

Type material: Holotype ơ : "CHINA [1a] - Yunnan, mts NW Dongchuan, $2350 \mathrm{~m}, 26^{\circ} 10^{\prime} 00^{\prime \prime} \mathrm{N}, 103^{\circ} 03^{\prime} 32^{\prime \prime E}$, trail side, 8.VIII.2014, V. Assing / Holotypus ơ Nazeris brevilobatus sp. n., det. V. Assing 2014” (cAss).

Paratypes: $3 \sigma^{\star} \sigma^{\star}, 3$ 우 운 same data as holotype (cAss); $3 \sigma^{\pi} \sigma^{*}, 5$ 우 우 [1 $\sigma^{*}, 4$ 우 우 teneral]: same data as holotype, but leg. M. Schülke (cSch, cAss).

Etymology: The specific epithet (Latin, adjective) alludes to the conspicuously short dorso-lateral apophyses of the aedeagus.
Description: Species of moderate size; body length $5.2-6.2 \mathrm{~mm}$; length of forebody $2.9-3.2 \mathrm{~mm}$. Coloration: body blackish-brown to blackish; legs and antennae yellowish.

Head (Fig. 1) weakly oblong, approximately 1.05 times as long as broad; lateral contours behind eyes smoothly curving towards posterior constriction in dorsal view, posterior angles obsolete; punctation very dense, not very coarse, and distinctly umbilicate; interstices forming narrow ridges, without microsculpture. Eyes approximately one third as long as distance from posterior margin of eye to posterior constriction in dorsal view, or nearly so. Antenna approximately $1.7 \mathrm{~mm}$ long.

Pronotum (Fig. 1) approximately 1.15 times as long as broad and 0.9 times as broad as head; punctation very dense and much coarser than that of head; midline posteriorly with short and narrow impunctate glossy elevation; lateral portions without distinct impressions, elevations, or callosities; interstices without microsculpture and glossy.

Elytra (Fig. 1) approximately 0.55 times as long as pronotum; humeral angles obsolete; punctation approximately as coarse and as dense as that of pronotum; interstices without microsculpture and glossy. Hind wings completely reduced. Metatarsomere I elongated, nearly as long as the combined length of II-V. 


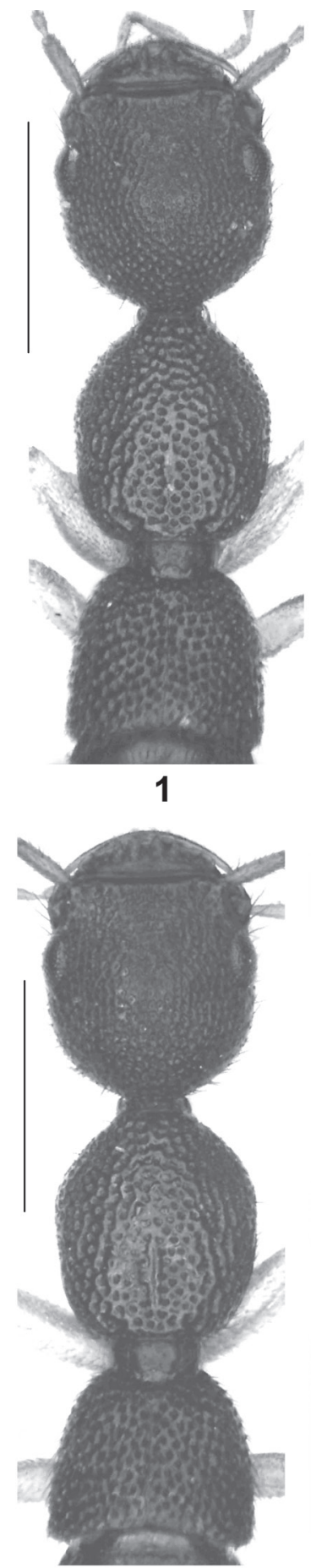

8

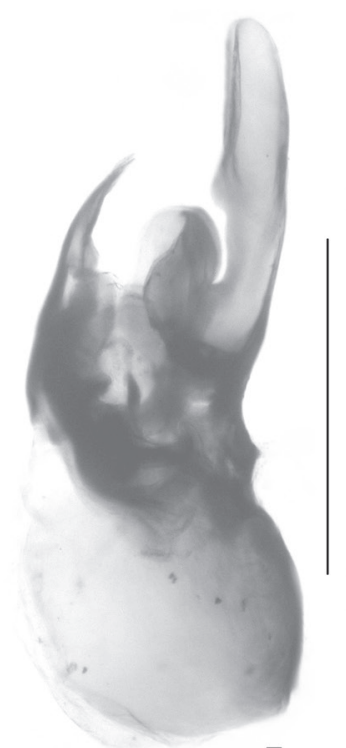

5

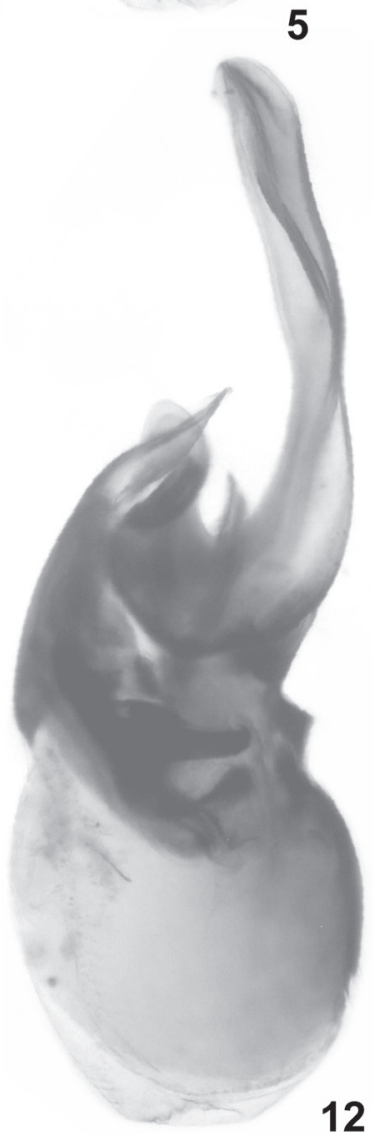

12

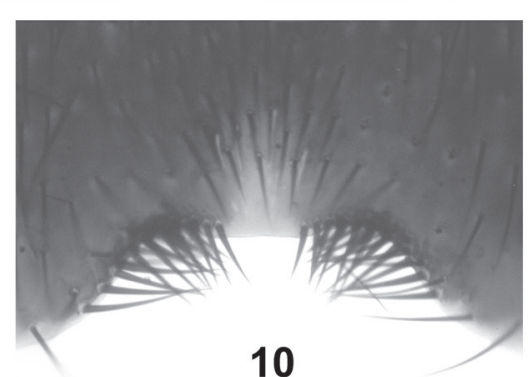

10

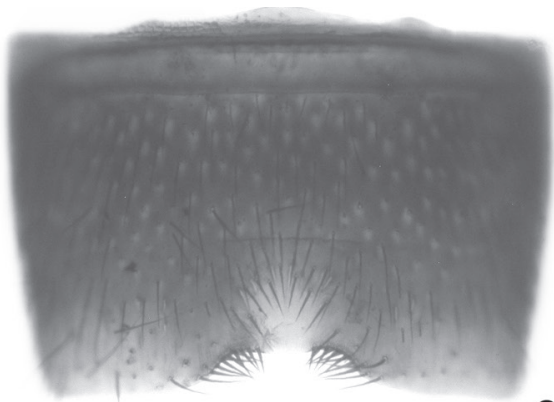

2
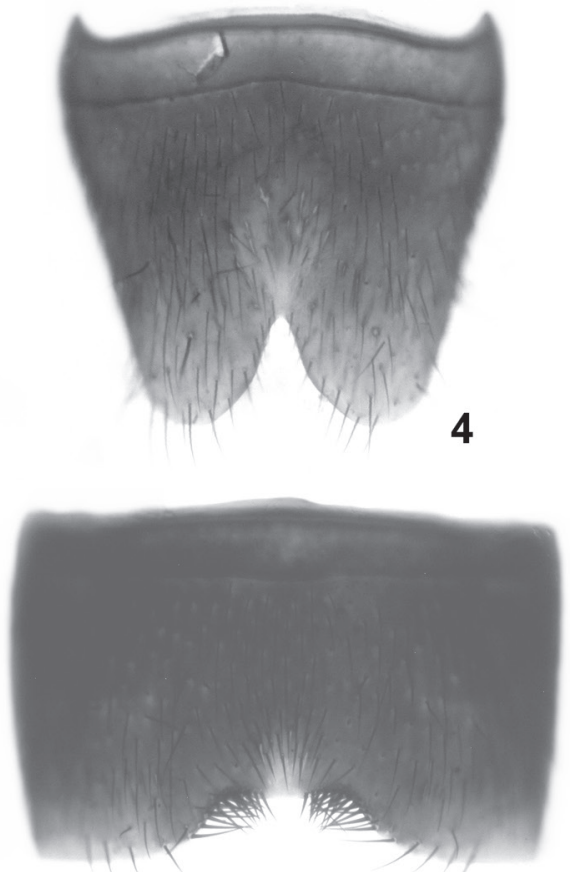

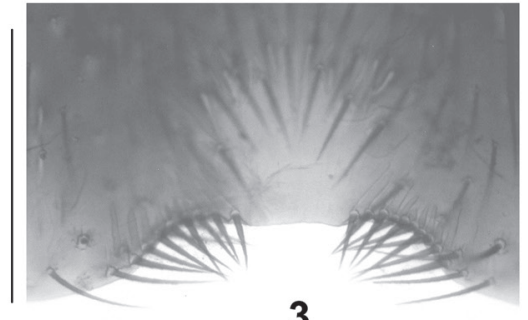

3
9

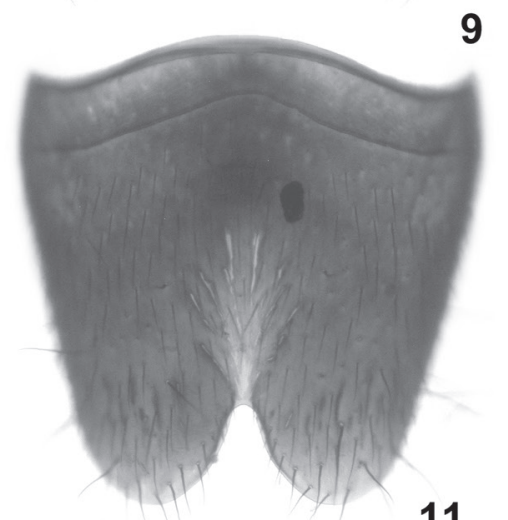

11

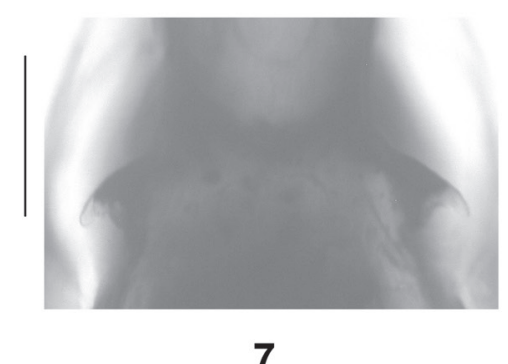

Figs 1-13: Nazeris brevilobatus sp. n. (1-7) and N. virilis sp. n. (8-13): forebody $(1,8)$; male sternite VII $(2,9)$; postero-median portion of male sternite VII $(3,10)$; male sternite VIII $(4,11)$; aedeagus in lateral and in ventral view $(5-6,12-13)$; basal portion of ventral process of aedeagus in ventral view (7). Scale bars: 1, 8: $1.0 \mathrm{~mm} ; 2,4-6,9,11-13: 0.5 \mathrm{~mm} ; 3,10: 0.2 \mathrm{~mm} ; 7: 0.1 \mathrm{~mm}$. 
Abdomen 1.15-1.20 times as broad as elytra; punctation coarse and dense on tergite III, becoming gradually less coarse and less dense towards posterior tergites; interstices of tergites III-VI without, those of tergites VII and VIII with very shallow microreticulation; posterior margin of tergite VII with narrow rudiment of a palisade fringe; posterior margin of tergite VIII strongly convex.

$\sigma^{*}$ : sternite VII (Fig. 2) approximately 1.5 times as broad as long, with shallow postero-median impression, this impression without pubescence in postero-median portion, posterior margin with distinct broad and shallow median excision, this excision with a lateral cluster of long black setae on either side (Fig. 3); sternite VIII (Fig. 4) transverse, approximately 1.1 times as broad as long, posterior excision acutely $\mathrm{V}$-shaped and approximately one-fourth as deep as length of sternite; aedeagus (Figs 5-6) 1.10-1.15 mm long; ventral process laterally compressed, ventrally divided along middle and sharply edged in apical portion, basally with a short and acute projection on either side (Fig. 7); dorso-lateral apophyses weakly sclerotized, very short, not reaching middle of ventral process, weakly curved, apically strongly dilated and obliquely truncate.

Comparative notes: Nazeris brevilobatus is readily distinguished from other previously described species recorded from Yunnan particularly by the conspicuous morphology of the aedeagus (short dorso-lateral apophyses; structure of the ventral process; projections at base of the ventral process) and by the distinctive shape and chaetotaxy of the male sternite VII.

Distribution and natural history: The type locality is situated to the northwest of Dongchuan, northeastern Yunnan (Map 2). The specimens were sifted from litter and the roots of herbs at and near a trail margin at an altitude of $2350 \mathrm{~m}$. Several of the paratypes are teneral.

\section{Nazeris virilis sp. $\mathrm{n}$.}

(Figs 8-13, Map 2)

Type material: Holotype $o^{*}$ : "CHINA [12] - Yunnan, mt. WNW Wuding, mix. forest, $25^{\circ} 38^{\prime} 45^{\prime \prime} \mathrm{N}, 102^{\circ} 06^{\prime} 55^{\prime \prime} \mathrm{E}$, 2390 m, 18.VIII.2014, V. Assing / Holotypus ơ Nazeris virilis sp. n., det. V. Assing 2014” (cAss).

Paratypes: $3 \sigma^{\star \top} o^{\star}, 2$ ㅇ 9 : same data as holotype (cAss); $1 \sigma^{\star *}:$ same data as holotype, but leg. M. Schülke (cSch); $120^{\top} \sigma^{\star}$, 4 우 우 [2 $\sigma^{\star} \sigma^{*}, 3$ 우 우 teneral]: "CHINA [12a] - Yunnan, mt. WNW Wuding, mix. forest, $25^{\circ} 38^{\prime} 45^{\prime \prime} \mathrm{N}, 102^{\circ} 06^{\prime} 55^{\prime \prime} \mathrm{E}$, 2390 m, 1.IX.2014, V. Assing" (cAss, MNHUB); $4 o^{\star} o^{\star}$, 1 ㅇ [1 $\sigma^{\star}$ teneral], same data, but leg. M. Schülke (cSch); $2 \sigma^{\star} o^{\star}, 1$ ㅇ [1 o $^{\star}$ teneral]: “CHINA [10] - Yunnan, mt. NW Wuding, mixed forest, $25^{\circ} 36^{\prime} 53^{\prime \prime N}, 102^{\circ} 18^{\prime} 59^{\prime \prime E}, 2190 \mathrm{~m}$, 17.VIII.2014, V. Assing" (cAss); $10^{\star}$ [teneral]: same data, but leg. M. Schülke (cSch).

Etymology: The specific epithet (Latin, adjective: manly, virile) alludes to the conspicuously large aedeagus.
Description: Species of moderate size; body length 5.5-6.7 mm; length of forebody $2.8-3.1 \mathrm{~mm}$. Coloration: body blackish; legs and antennae yellowish.

Head (Fig. 8) weakly oblong, approximately 1.05 times as long as broad; lateral contours behind eyes smoothly curving towards posterior constriction in dorsal view, posterior angles obsolete; punctation very dense, not very coarse, and distinctly umbilicate; interstices forming narrow ridges, without microsculpture. Eyes approximately one-third as long as distance from posterior margin of eye to posterior constriction in dorsal view, or nearly so. Antenna 1.6-1.7 mm long.

Pronotum (Fig. 8) approximately 1.15 times as long as broad and $0.90-0.95$ times as broad as head; punctation very dense and much coarser than that of head; midline posteriorly with short and narrow impunctate glossy elevation; lateral portions without distinct impressions, elevations, or callosities; interstices without microsculpture and glossy.

Elytra (Fig. 8) 0.50-0.55 times as long as pronotum; humeral angles obsolete; punctation approximately as coarse and as dense as that of pronotum; interstices without microsculpture and glossy. Hind wings completely reduced. Metatarsomere I elongated, but distinctly shorter than the combined length of II-V.

Abdomen approximately 1.2 times as broad as elytra; punctation moderately coarse and very dense on tergites III-VI, finer and sparser on tergites VII and VIII; interstices of tergites III-VI without, those of tergites VII and VIII with very shallow microreticulation; posterior margin of tergite VII with narrow rudiment of a palisade fringe; posterior margin of tergite VIII strongly convex.

$\sigma^{\star}$ : sternite VII (Fig. 9) approximately 1.65 times as broad as long, with shallow postero-median impression, posterior margin with distinct broad median excision, this excision with a lateral cluster of long black setae on either side (Fig. 10); sternite VIII (Fig. 11) approximately as broad as long and with strongly convex anterior margin, posterior excision acutely $\mathrm{V}$-shaped and approximately 0.22 times as deep as length of sternite; aedeagus (Figs 12-13) conspicuously long (approximately $1.6 \mathrm{~mm}$ ); ventral process deeply incised apico-ventrally, basally with a short and acute projection on either side; dorsolateral apophyses weakly sclerotized, very short, far from reaching middle of ventral process, weakly curved, apically distinctly dilated and obliquely truncate.

Comparative notes: As can be inferred from the similarly derived morphology of the aedeagus (very long ventral process with median carina; dorso-lateral apophyses conspicuously short, weakly sclerotized, apically dilated, and obliquely truncate) and from the similar modifications of the male sternite VII (posteriorly with a pronounced concavity and with a pair of clusters of modified setae), $N$. virilis is undoubtedly closely related to N. brevilobatus, from which it differs by the more pronounced posterior concavity and the more pronounced clusters of setae of the male sternite VII, the less deep posterior excision of 
the differently shaped male sternite VIII (not transverse), and by the much longer ventral process of the aedeagus.

Distribution and natural history: The species was discovered in two localities to the northwest and westnorthwest of Wuding, approximately 75 and $90 \mathrm{~km}$ to the northwest of Kunming (Map 2). The partly teneral specimens were sifted from litter in a mixed forest margin with alder and pine and in a degraded mixed forest with alder, oak, and pine at altitudes of 2390 and $2190 \mathrm{~m}$, respectively.

\section{Nazeris constrictus sp. $\mathrm{n}$.}

(Figs 14-19, 32, Map 2)

Type material: Holotype $\sigma^{\star}$ [slightly teneral]: “ CHINA [13] - Yunnan, mt. SE Gejiu, graveyard with pine, $23^{\circ} 18^{\prime} 27^{\prime \prime N}, 103^{\circ} 11^{\prime} 41^{\prime} \mathrm{E}, 2400 \mathrm{~m}, 20 . \mathrm{VIII} .2014$, V. Assing / Holotypus ơ Nazeris constrictus sp. n., det. V. Assing 2014" (cAss).

Paratypes: $2 \sigma^{\star} o^{\star}$ [both teneral]: same data as holotype (cAss); $10^{\star}$ [teneral]: same data as holotype, but leg. M. Schülke (cSch); 2 ㅇ [both teneral]: "CHINA [17] Yunnan, S Gejiu, $23^{\circ} 17^{\prime} 14^{\prime \prime} \mathrm{N}, 103^{\circ} 08^{\prime} 41^{\prime} \mathrm{E}, 1860 \mathrm{~m}$, road margin with shrubs, 21.VIII.2014, V. Assing” (cAss); 1 ㅇ [teneral], same data, but leg. M. Schülke (cSch).

Etymology: The specific epithet (Latin, adjective) alludes to the subapically constricted ventral process of the aedeagus.

Description: Moderately large species; body length 5.6-6.7 mm; length of forebody 3.1-3.5 mm. Coloration: body blackish; legs and antennae yellowish, with antennomere I somewhat darker.

Head (Fig. 14) moderately oblong, 1.04-1.08 times as long as broad; lateral contours behind eyes smoothly and weakly curving towards posterior constriction in dorsal view, posterior angles obsolete; punctation very dense, not very coarse, and distinctly umbilicate; interstices forming narrow ridges, without microsculpture. Eyes approximately one-third as long as distance from posterior margin of eye to posterior constriction in dorsal view. Antenna approximately $1.8 \mathrm{~mm}$ long.

Pronotum (Fig. 14) approximately 1.2 times as long as broad and 0.90-0.95 times as broad as head; punctation very dense and much coarser than that of head; midline posteriorly with short and narrow impunctate glossy elevation; lateral portions without distinct impressions or elevations; interstices without microsculpture and glossy. Elytra (Fig. 14) approximately 0.55 times as long as pronotum; humeral angles obsolete; punctation approximately as coarse and as dense as that of pronotum; interstices without microsculpture and glossy. Hind wings completely reduced. Metatarsomere I elongated, nearly as long as the combined length of II-V.

Abdomen 1.20-1.25 times as broad as elytra; punctation coarse and very dense on tergites III-VI, slightly finer and slightly sparser on tergites VII and VIII; interstices without microreticulation; posterior margin of tergite VII with narrow rudiment of a palisade fringe; posterior margin of tergite VIII strongly convex.

$\mathrm{o}^{\star}$ : sternite VII (Fig. 15) approximately 1.6 times as broad as long, with shallow postero-median impression, this impression with moderately stout black setae, posterior margin with shallow median concavity, this concavity with a lateral cluster of long black setae on either side (Fig. 16); sternite VIII (Fig. 17) oblong, nearly 1.1 times as long as broad and with moderately convex anterior margin, posterior excision narrow and anteriorly acute, approximately one-third as deep as length of sternite; aedeagus (Figs 18-19) $1.65 \mathrm{~mm}$ long; ventral process very long and subapically constricted in ventral view, apico-ventrally deeply incised in the middle, on either side of this incision with pronounced carina, basally without a short and acute projection on either side; dorso-lateral apophyses weakly sclerotized, very short, not reaching middle of ventral process, weakly curved, apically strongly dilated and obliquely truncate (Fig. 32).

Comparative notes: Based on the similarly derived morphology of the aedeagus, as well as on the conspicuous modifications of the male sternite VII, N. constrictus is closely related to N. brevilobatus and especially to $N$. virilis. It differs from both species by slightly larger body size, the modified dark setae in the postero-median impression of the male sternite VII, the oblong and posteriorly much more deeply incised male sternite VIII, and by the subapically constricted ventral process of the aedeagus.

Distribution and natural history: The known distribution is confined to two localities to the south and southeast of Gejiu, southeastern Yunnan (Map 2). The more or less distinctly teneral specimens were sifted from leaf litter, herb roots, and moss in a graveyard with scattered pine trees and on a grassy slope with shrubs near a road at altitudes of 2400 and $1860 \mathrm{~m}$, respectively.

\section{Nazeris claviger sp. $\mathrm{n}$.}

(Figs 20-25, 33, Map 2)

Type material: Holotype $0^{*}$ : "CHINA [20] - Yunnan, mt. W Gejiu, mixed forest, 2324'13"N, 10307'28"E, 1990 m, 23.VIII.2014, V. Assing / Holotypus o Nazeris claviger sp. n., det. V. Assing 2014" (cAss).

Paratypes: $13 \sigma^{\star} o^{\star}, 6$ 우 우 [3 $\sigma^{\star} o^{\star}, 2$ ㅇ ㅇ t teneral]: same data as holotype (cAss, MNHUB); $13 o^{\star} \sigma^{\star}, 12$ 우 우 [1 $\sigma^{\star}, 2$ 우 우 teneral]: same data as holotype, but leg. M. Schülke (cSch); $4 o^{\star} o^{\star}, 4$ 우 우 [1 o $^{\star}, 2$ 우 ㅇt teneral]: “CHINA [20a] - Yunnan, $\mathrm{mt}$. W Gejiu, mixed forest, $23^{\circ} 24^{\prime} 13^{\prime \prime N}, 103^{\circ} 07^{\prime} 28^{\prime \prime} \mathrm{E}$, 1990 m, 24.VIII.2014, V. Assing" (cAss, MNHUB); 1 ơ , 2 우 우 [1 $\sigma^{\star}$ teneral]: same data, but leg. M. Schülke (cSch); $20^{\star} o^{\top}, 3$ 우 우 [1 우 teneral]: "CHINA [20b] - Yunnan, mt. W Gejiu, mixed forest, $23^{\circ} 24^{\prime} 13^{\prime \prime} \mathrm{N}, 103^{\circ} 07^{\prime} 28^{\prime \prime} \mathrm{E}$, 


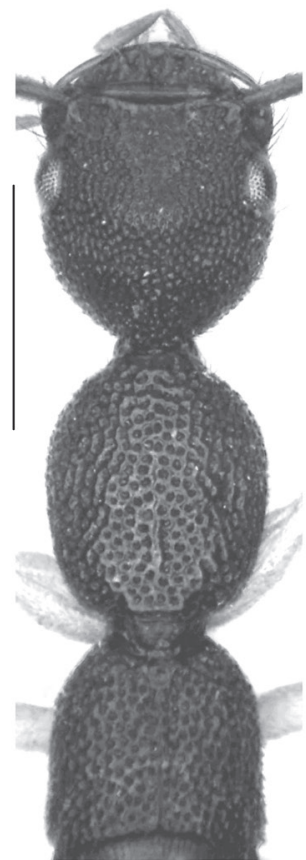

14

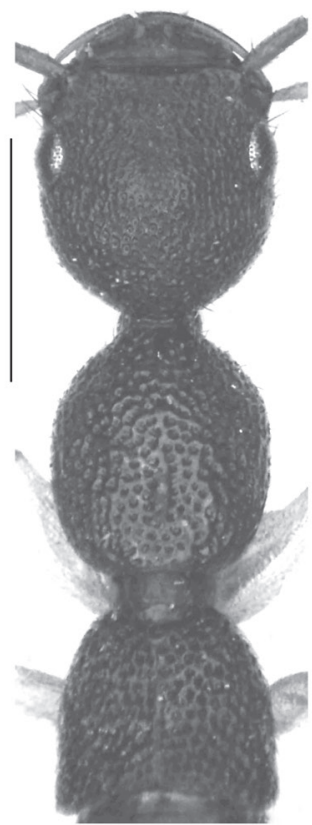

20

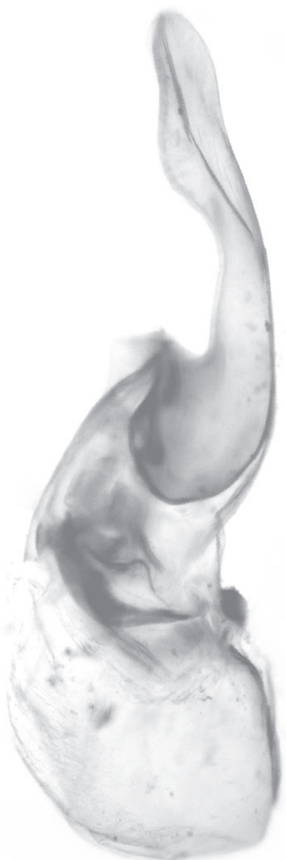

18

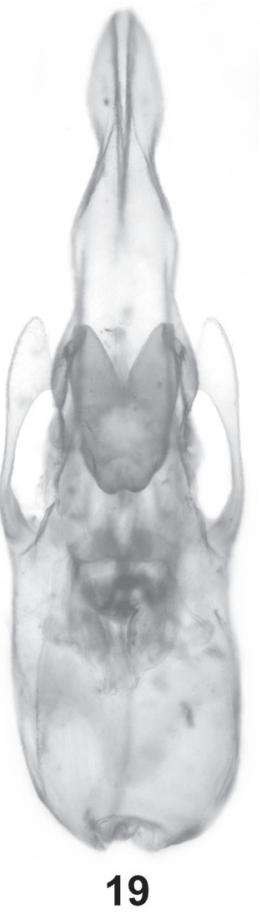

19

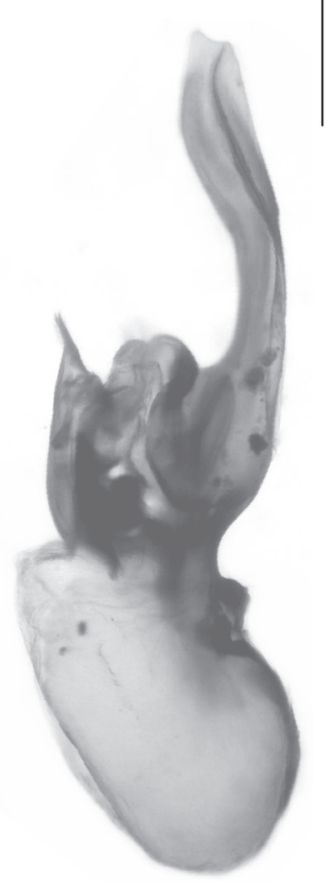

24

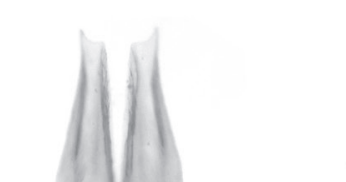

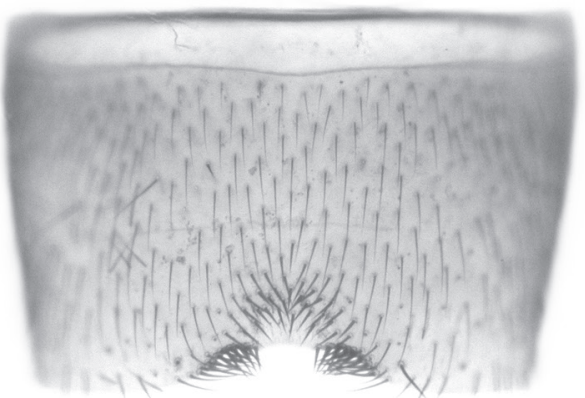

15
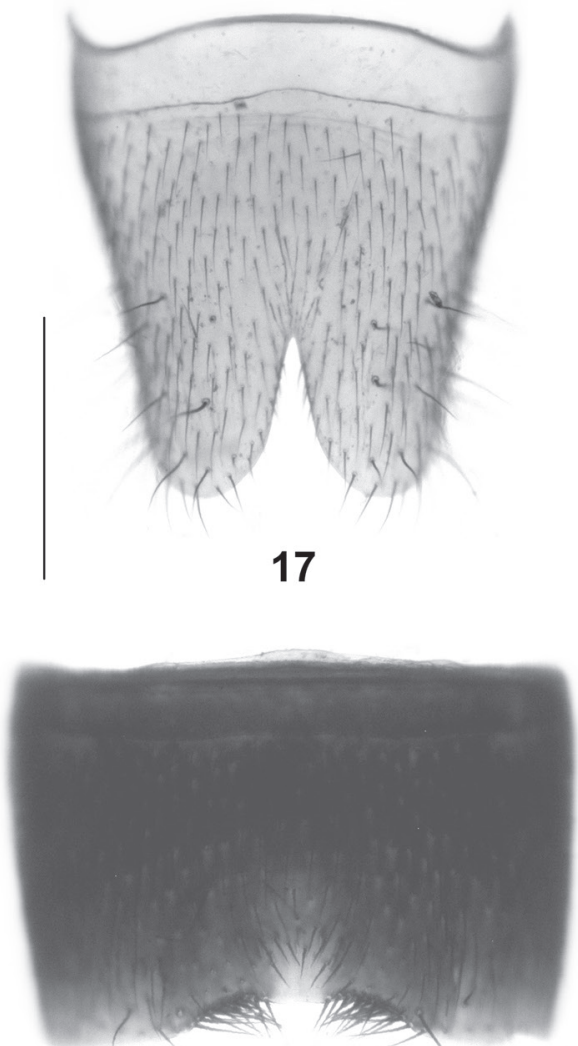

21

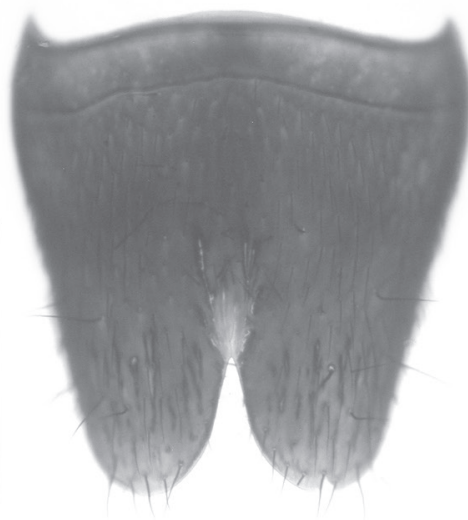

23

16

Figs 14-25: Nazeris constrictus sp. n. (14-19) and N. claviger sp. n. (20-25): forebody $(14,20)$; male sternite VII (15, 21); posteromedian portion of male sternite VII $(16,22)$; male sternite VIII $(17,23)$; aedeagus in lateral and in ventral view $(18-19,24-25)$. Scale bars: 14, 20: $1.0 \mathrm{~mm} ; 15,17-19,21,23-25: 0.5 \mathrm{~mm} ; 16,22: 0.2 \mathrm{~mm}$. 
1990 m, 25.VIII.2014, V. Assing" (cAss, MNHUB); 4 o o o [1 teneral]: same data, but leg. M. Schülke (cSch).

Etymology: The specific epithet (Latin, noun in apposition: carrier of clubs) alludes to the distinctly club-shaped dorso-lateral apophyses.

Description: Moderately large species; body length 5.8-7.5 mm; length of forebody 3.1-3.5 mm. Coloration: body blackish; legs and antennae yellowish, with antennomere I often slightly darker.

Head (Fig. 20) weakly oblong, approximately 1.05 times as long as broad; lateral contours behind eyes smoothly and weakly curving towards posterior constriction in dorsal view, posterior angles obsolete; punctation very dense, moderately coarse, and distinctly umbilicate; interstices forming narrow ridges, without microsculpture. Eyes approximately one-third as long as distance from posterior margin of eye to posterior constriction in dorsal view. Antenna 1.8-2.0 mm long.

Pronotum (Fig. 20) approximately 1.2 times as long as broad and 0.90-0.95 times as broad as head; punctation very dense and much coarser than that of head; midline posteriorly with short and narrow impunctate glossy elevation; lateral portions without distinct impressions or elevations; interstices without microsculpture and glossy.

Elytra (Fig. 20) 0.51-0.55 times as long as pronotum; humeral angles obsolete; punctation approximately as coarse and as dense as that of pronotum; interstices without microsculpture and glossy. Hind wings completely reduced. Metatarsomere I elongated, nearly as long as the combined length of II-V.

Abdomen 1.20-1.25 times as broad as elytra; punctation coarse and very dense on tergites III-VI, slightly finer and slightly sparser on tergites VII and VIII; interstices usually without microreticulation, rarely with shallow traces near posterior margin of tergite VII; posterior margin of tergite VII usually with, rarely without narrow rudiment of a palisade fringe; posterior margin of tergite VIII strongly convex.

$\sigma^{*}$ : sternite VII (Fig. 21) approximately 1.6 times as broad as long, with shallow postero-median impression, posterior margin with shallow median concavity, this concavity with a dense lateral cluster of long black setae on either side (Fig. 22); sternite VIII (Fig. 23) approximately as long as broad and with moderately convex anterior margin, posterior excision narrow and anteriorly acute, slightly less than 0.3 times as deep as length of sternite; aedeagus (Figs 24-25) approximately $1.6 \mathrm{~mm}$ long; ventral process very long, apico-ventrally deeply incised in the middle, apically of distinctive shape both in ventral and in lateral view, basally without a short semicircular projection on either side; dorso-lateral apophyses weakly sclerotized, very short, far from reaching middle of ventral process, weakly curved, strongly dilated in apical half (club-shaped) (Fig. 33).
Comparative notes: The morphology of the aedeagus and the derived shape and chaetotaxy of the male sternite VII leave no doubt that $N$. claviger belongs to the $N$. brevilobatus group. It is distinguished from other species of this group particularly by the chaetotaxy of the male sternite VII (more pronounced posterior clusters of black setae) and by the morphology of the aedeagus (shapes of ventral process and of dorso-lateral apophyses).

Distribution and natural history: The type locality is situated in a mountain close to, and to the west of, Gejiu in southeastern Yunnan (Map 2). The partly teneral specimens were sifted from litter and various debris in a mixed forest at an altitude of nearly $2000 \mathrm{~m}$. For an illustration of the type locality see Assing (in press: figure 8).

\section{Nazeris discissus sp. $\mathrm{n}$.}

(Figs 26-31, Map 2)

Type material: Holotype $0^{\star}:$ "CHINA [22a] - Yunnan, SE Pingbian, primary forest, $22^{\circ} 54^{\prime} 31^{\prime} \mathrm{N}, 103^{\circ} 41^{\prime} 44^{\prime} \mathrm{E}, 2100$ m, 28.VIII.2014, V. Assing / Holotypus ơ Nazeris discissus sp. n., det. V. Assing 2014" (cAss).

Paratypes: $3 \sigma^{\star} o^{\star}$ [all teneral]: same data as holotype (cAss); $10^{\star}, 1$ i [both teneral]: same data as holotype, but leg. M. Schülke (cSch); 1 o , 3 ㅇ ㅇ [all teneral]: "CHINA [22] - Yunnan, SE Pingbian, primary forest, $22^{\circ} 54^{\prime} 31^{\prime \prime N}$, $103^{\circ} 41^{\prime} 44^{\prime \prime E}, 2100 \mathrm{~m}, 27$. VIII.2014, V. Assing" (cAss, MNHUB).

Etymology: The specific epithet is the past participle of the Latin verb discindere (to cut apart) and alludes to the apically deeply divided ventral process of the aedeagus.

Description: Rather large species; body length 6.5-8.5 mm; length of forebody $3.8-4.1 \mathrm{~mm}$. Coloration: body blackish; legs and antennae yellowish, with antennomeres I-III pale-redddish.

Head (Fig. 26) weakly oblong, approximately 1.05 times as long as broad; lateral contours behind eyes smoothly and weakly curving towards posterior constriction in dorsal view, posterior angles obsolete; punctation very dense, not very coarse, and distinctly umbilicate; interstices forming narrow ridges, without microsculpture. Eyes less than one-third as long as distance from posterior margin of eye to posterior constriction in dorsal view. Antenna 2.2-2.4 mm long.

Pronotum (Fig. 26) approximately 1.2 times as long as broad and 0.9 times as broad as head; punctation very dense and much coarser than that of head; midline posteriorly with short and narrow impunctate glossy elevation; postero-lateral portions with glossy callosities; interstices without microsculpture and glossy.

Elytra (Fig. 26) 0.52-0.55 times as long as pronotum; humeral angles obsolete; punctation approximately as coarse and as dense as that of pronotum; interstices with- 


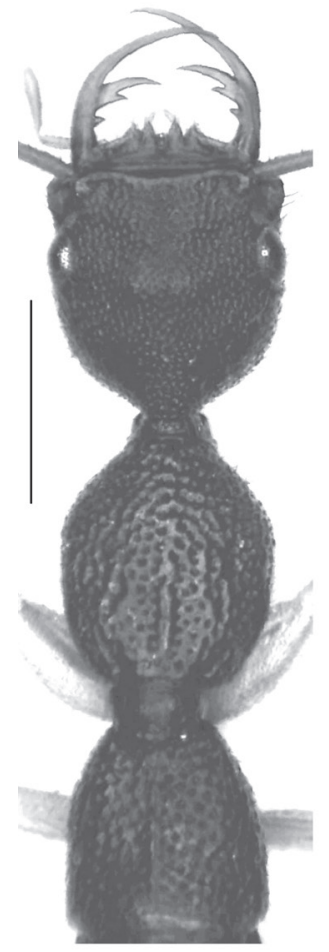

26

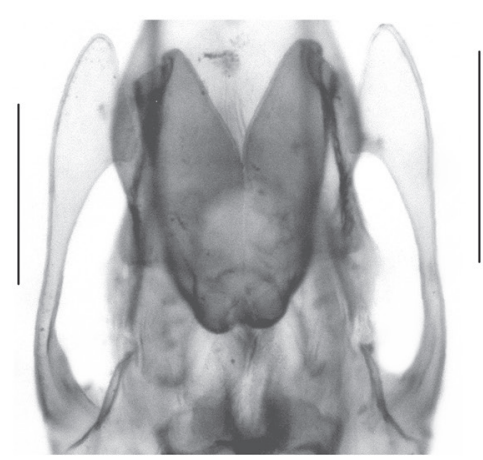

32

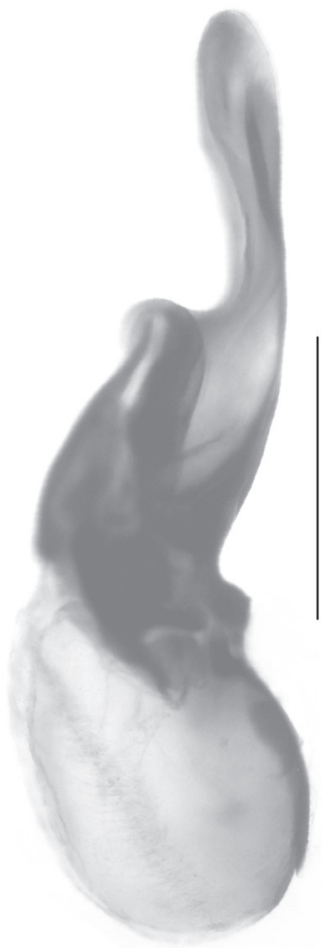

30

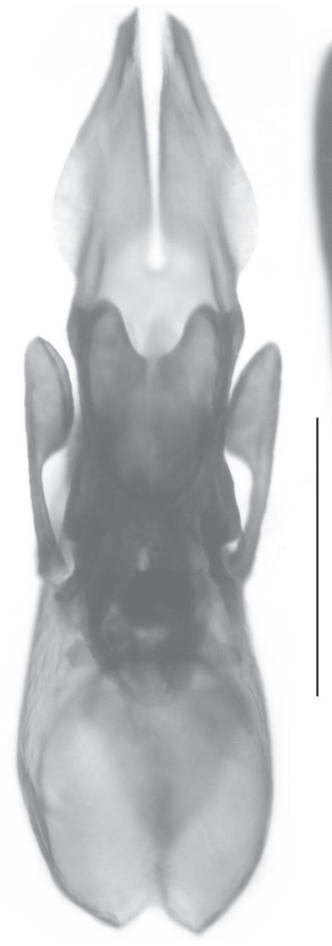

31

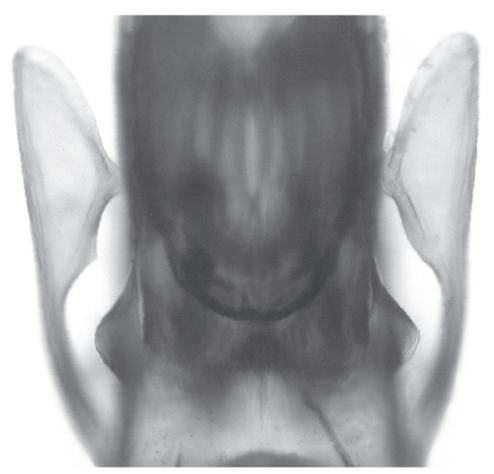

33

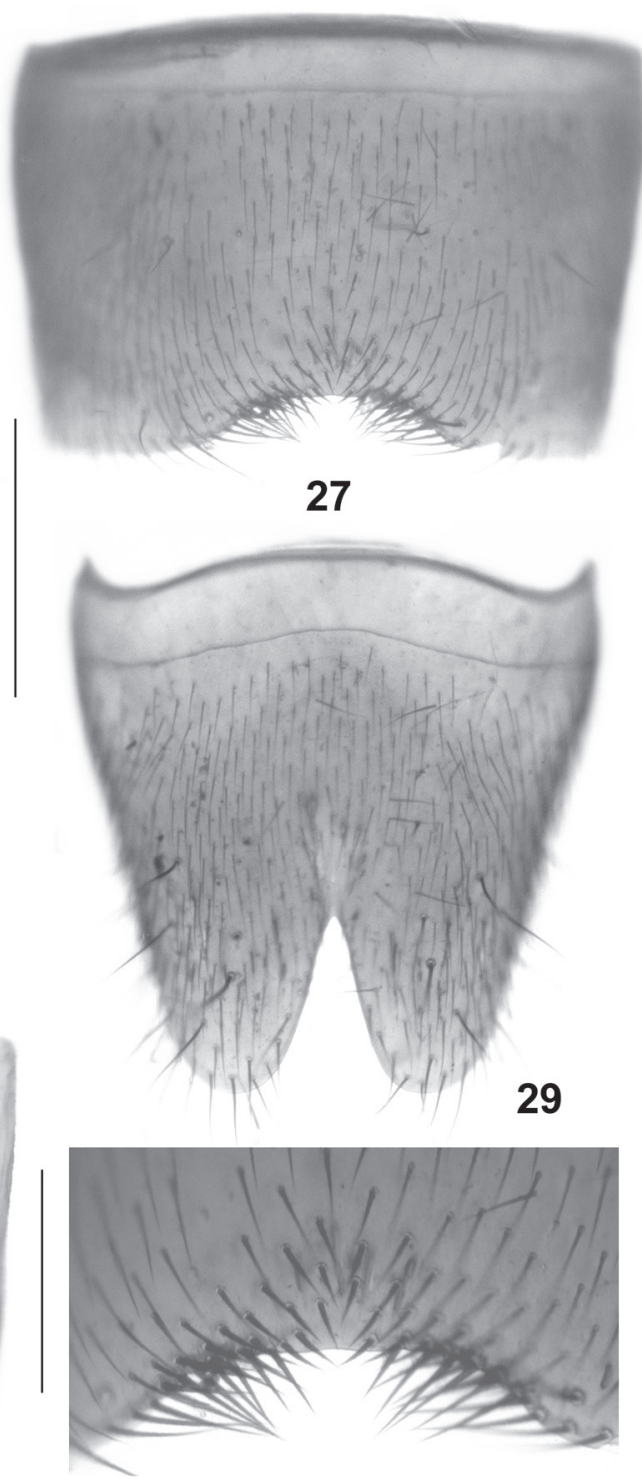

28

Figs 26-33: Nazeris discissus sp. n. (26-31), N. constrictus sp. n. (32), and N. claviger sp. n. (33): forebody (26); male sternite VII (27); postero-median portion of male sternite VII (28); male sternite VIII (29); aedeagus in lateral and in ventral view (30-31); median portion of aedeagus in ventral view (32-33). Scale bars: $26: 1.0 \mathrm{~mm} ; 27,29-31: 0.5 \mathrm{~mm} ; 28,32-33: 0.2 \mathrm{~mm}$.

out microsculpture and glossy. Hind wings completely reduced. Metatarsomere I elongated, shorter than the combined length of II-V.

Abdomen 1.20-1.25 times as broad as elytra; punctation moderately coarse and conspicuously dense on tergites III-VI, nearly as dense on tergite VII, and somewhat sparser and finer on tergite VIII; tergites III-VI and anterior portion of tergite VII without, tergite VIII and posterior portion of tergite VII with very shallow microreticulation; posterior margin of tergite VII with narrow rudiment of a palisade fringe; posterior margin of tergite VIII strongly convex.

$\mathrm{o}^{7}$ : sternite VII (Fig. 27) approximately 1.5 times as broad as long, with shallow postero-median impression, this impression with short black setae, posterior margin with shallow median concavity, this concavity with a dense lateral cluster of long black setae on either side
(Fig. 28); sternite VIII (Fig. 29) approximately as long as broad and with weakly convex anterior margin, posterior excision narrowly V-shaped, approximately one-third as deep as length of sternite; aedeagus (Figs 30-31) approximately $1.7 \mathrm{~mm}$ long; ventral process very long, apico-ventrally deeply incised in the middle, apically of distinctive shape particularly in ventral view, basally with an obtusely angled projection on either side; dorso-lateral apophyses weakly sclerotized, very short, not reaching middle of ventral process, strongly dilated in apical half.

Comparative notes: Nazeris discissus, too, clearly belongs to the N. brevilobatus group. It shares the synapomorphies (modifications of the male sternite VII and the aedeagus) with other species of this group, but differs by larger body size, the shapes and chaetotaxy of the male 
sternites VII and VIII, and particularly by the morphology of the aedeagus (shapes of the ventral process and of the dorso-lateral apophyses).

Distribution and natural history: The type locality is situated in the Dawei Shan Virgin Forest Park near Pingbian, southeastern Yunnan (Map 2). The specimens were sifted from leaf litter in a primary subtropical broadleaved forest at an altitude of $2100 \mathrm{~m}$, together with $N$. semifissus and numerous other undescribed species of Staphylinidae. All the paratypes are more or less distinctly teneral.

\section{Nazeris lamellatus sp. n.}

(Figs 34-39, Map 3)

Type material: Holotype ơ : "CHINA [21] - Yunnan, NNE Pingbian, broad-leaved for., $23^{\circ} 00^{\prime} 39^{\prime \prime N}, 103^{\circ} 42^{\prime} 10^{\prime} \mathrm{E}$, 1500 m, 26.VIII.2014, V. Assing / Holotypus o Nazeris lamellatus sp. n., det. V. Assing 2014" (cAss).

Paratype $\sigma^{\top}$ : same data as holotype (cAss).
Description: Slender species of moderate size; body length $6.7-7.0 \mathrm{~mm}$; length of forebody $3.5-3.6 \mathrm{~mm}$. Coloration: body black; legs and antennae yellowish, with antennomere I slightly darker.

Head (Fig. 34) moderately oblong, 1.06-1.07 times as long as broad, with moderately pronounced median elevation; lateral contours behind eyes smoothly curving towards posterior constriction in dorsal view, posterior angles obsolete; punctation very dense, rather coarse, rather shallow, partly confluent, and distinctly umbilicate; interstices forming narrow ridges, without microsculpture. Eyes slightly more than one-third as long as distance from posterior margin of eye to posterior constriction in dorsal view. Antenna approximately $2.0 \mathrm{~mm}$ long.

Pronotum (Fig. 34) slender, approximately 1.25 times as long as broad and 0.9 times as broad as head; punctation very dense and much coarser than that of head; midline with narrow and rather long impunctate glossy elevation; lateral portions with uneven surface, with weakly pronounced longitudinal elevations without punctures; interstices without microsculpture and glossy.

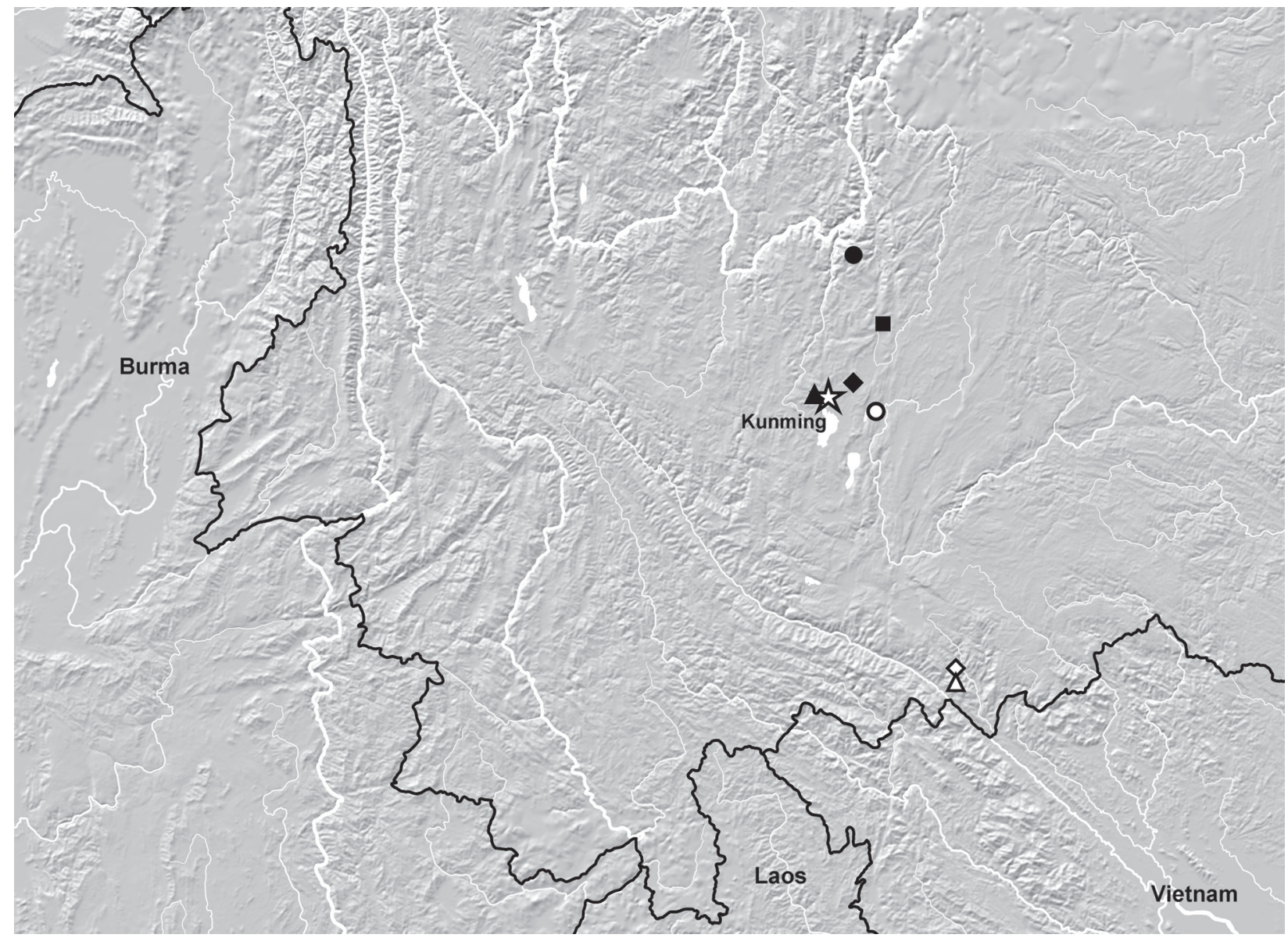

Map 3: Distribution of Nazeris species in eastern Yunnan (N. zhangi lineage: black symbols): N. clavilobatus sp. n. (black circle); N. conicus sp. n. (black square); N. bulbosus sp. n. (black diamond); N. zhangi WaTANABE \& Xiao (black triangle), N. fibulatus sp. n. (white circle); N. lamellatus sp. n. (white diamond); N. semifissus sp. n. (white triangle).

Etymology: The specific epithet (Latin, adjective) alludes to the semi-membranous, very weakly sclerotized ventral process of the aedeagus.
Elytra (Fig. 34) approximately 0.55 times as long as pronotum; humeral angles obsolete; dorsal surface depressed; punctation somewhat irregular and weakly defined, less coarse than that of pronotum; interstices with- 


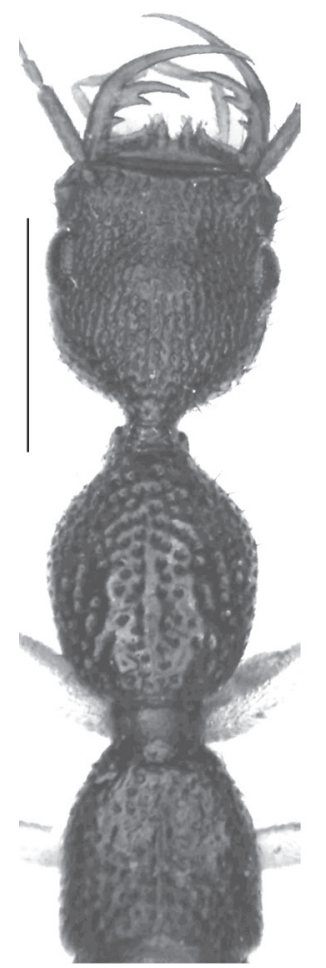

34

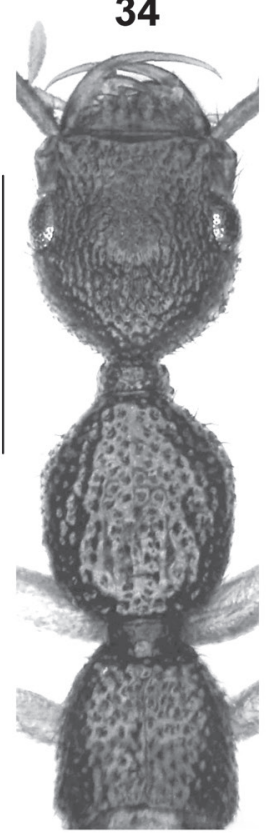

40

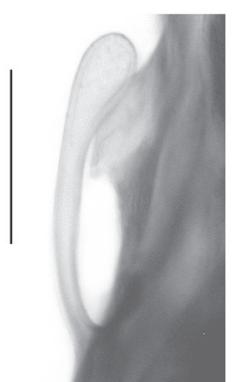

39

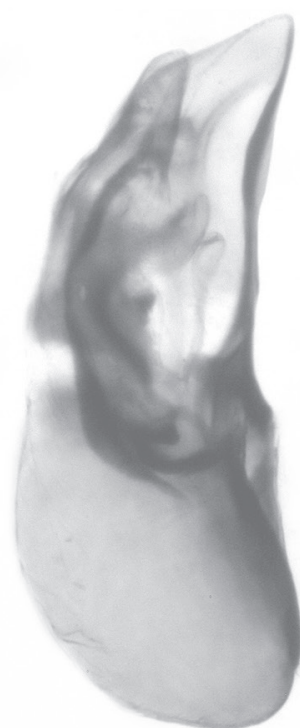

37

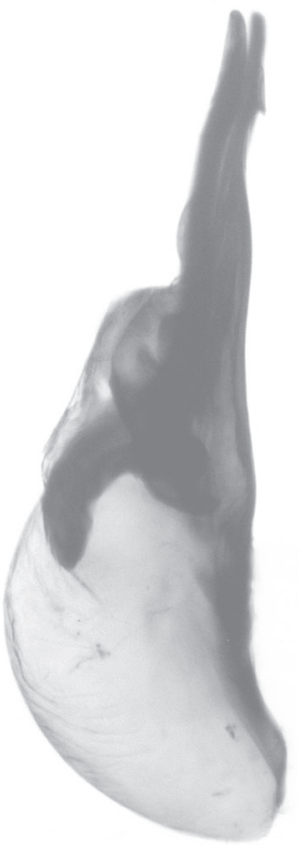

44

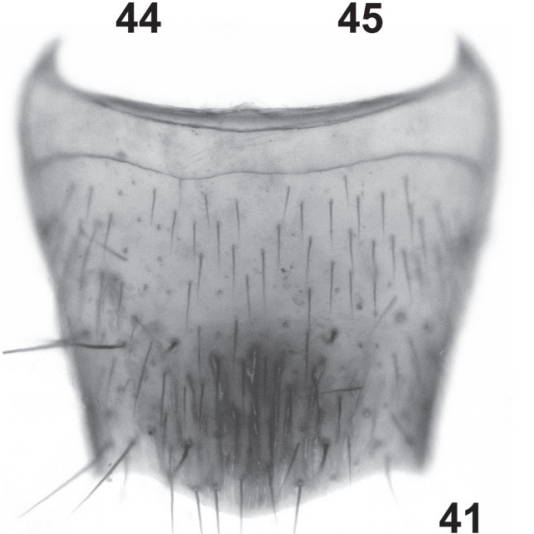

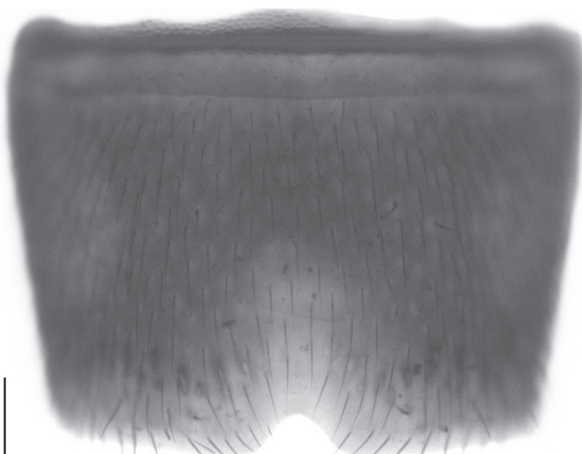

35

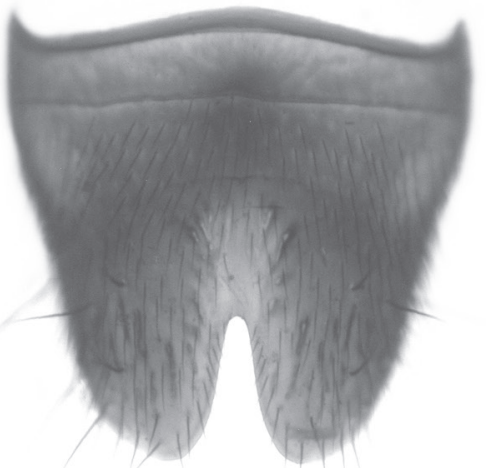

36

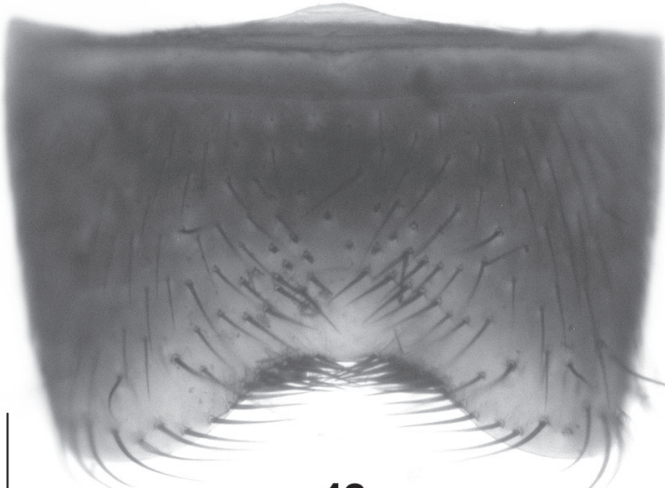

42

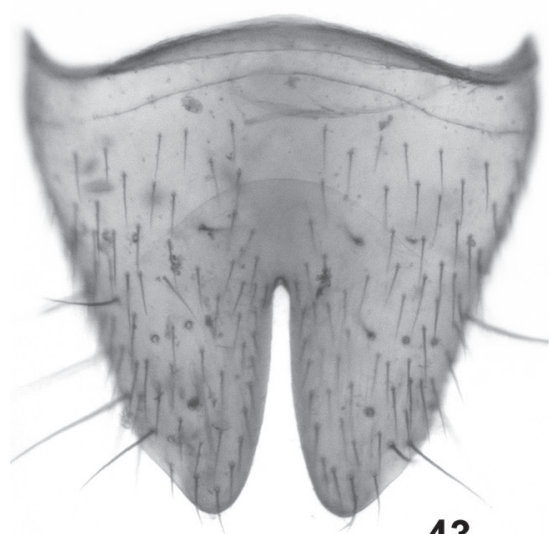

43

Figs 34-45: Nazeris lamellatus sp. n. (34-39) and N. semifissus sp. n. (40-45): forebody (34, 40); male sternite VII (35, 42); male sternite VIII $(36,43)$; aedeagus in lateral and in ventral view (37-38, 44-45); left dorso-lateral apophysis (39); tergite VIII (41). Scale bars: 34, 40: $1.0 \mathrm{~mm}$; 35-38, 41-45: $0.5 \mathrm{~mm}$; 39: $0.1 \mathrm{~mm}$. 
out microsculpture and glossy. Hind wings completely reduced. Metatarsomere I elongated, nearly as long as the combined length of II-V.

Abdomen approximately 1.2 times as broad as elytra; punctation coarse and dense on tergites III-VI, slightly less dense and finer on tergite VII; interstices without microreticulation; posterior margin of tergite VII without narrow rudiment of a palisade fringe; posterior margin of tergite VIII strongly convex.

$\sigma^{\top}$ : sternite VII (Fig. 35) moderately transverse, approximately 1.35 times as broad as long, posterior margin with a conspicuous median concavity; sternite VIII (Fig. 36) weakly transverse, approximately 1.05 times as broad as long, posterior excision very narrowly $\mathrm{V}$-shaped and approximately one-third as deep as length of sternite; aedeagus (Figs 37-38) approximately $0.85 \mathrm{~mm}$ long; ventral process very weakly sclerotized and with semimembranous ventral and lateral portions; dorso-lateral apophyses (Fig. 39) weakly sclerotized, apically slightly dilated, and short, approximately half as long as ventral process.

Comparative notes: Nazeris lamellatus is distinguished from all other congeners recorded from Yunnan by the completely different shape of the male sternite VII and the completely different morphology of the aedeagus, from most other species known from eastern Yunnan also by the median elevation, by the callosities and irregularly spaced punctation of the lateral portions of the pronotum, by the distinctly depressed elytra with somewhat irregular punctation, and by the shape of the posterior excision of the male sternite VIII. Among the described species of Nazeris, N. lamellatus may be most closely related to N. odzisan WATANABE, 1996 from North Vietnam, as can be inferred from the similar shape of the male sternite VIII (deep and narrow posterior excision), the presence of a posterior median concavity of the male sternite VII, and from the similar general morphology (shape of ventral process; short dorso-lateral apophyses) of the aedeagus. Based on the illustrations provided with the original description of N. odzisan, N. lamellatus differs from this species by the shape and chaetotaxy of the male sternite VII (N. odzisan: posterior concavity very small; sternite with long and pronounced median impression, this impression without pubescence), by the different contours (both in lateral and in ventral view) of the ventral process of the aedeagus, and by the even shorter and apically more distinctly dilated dorsolateral apophyses. For illustrations of N. odzisan see WATANABE (1996).

Distribution and natural history: The type locality is situated to the north-northeast of Pingbian, in the periphery of the Dawei Shan Virgin Forest Park in southeastern Yunnan (Map 3). The specimens were sifted from litter in a subtropical broad-leaved forest at an altitude of $1500 \mathrm{~m}$.

\section{Nazeris semifissus sp. $\mathrm{n}$.}

(Figs 40-45, Map 3)

Type material: Holotype $0^{\top}$ : "CHINA [22a] - Yunnan, SE Pingbian, primary forest, $22^{\circ} 54^{\prime} 31^{\prime \prime} \mathrm{N}, 103^{\circ} 41^{\prime} 44^{\prime \prime} \mathrm{E}$, 2100 m, 28.VIII.2014, V. Assing / Holotypus ơ Nazeris semifissus sp. n., det. V. Assing 2014" (cAss).

Paratypes: $1 \sigma^{\circ}, 2$ ㅇ $\%$ : same data as holotype (cAss); $4 \sigma^{\lambda} \sigma^{\top}$ : same data as holotype, but leg. M. Schülke (cSch, cAss); 1 o : "CHINA [22] - Yunnan, SE Pingbian, primary forest, $22^{\circ} 54^{\prime} 31^{\prime \prime N}, 103^{\circ} 41^{\prime} 44^{\prime \prime} \mathrm{E}, 2100 \mathrm{~m}, 27 . \mathrm{VIII} .2014$, V. Assing" (cAss).

Etymology: The specific epithet (Latin, adjective: halfdivided) alludes to the conspicuously long and narrow posterior incision of the male sternite VIII.

Description: Species of moderate size; body length $5.0-6.2 \mathrm{~mm}$; length of forebody $2.8-3.1 \mathrm{~mm}$. Coloration: head dark-reddish to dark-brown; pronotum dark-brown to blackish-brown; elytra dark-reddish to reddish-brown; abdominal segments III-VI dark-reddish to reddishbrown, segment VII dark-brown to blackish with narrowly reddish posterior margin, and segments VIII-X reddish-yellow with the posterior portion of tergite VIII more or less distinctly and more or less extensively infuscate (Fig. 41); legs and antennae yellowish, with antennomere I slightly darker.

Head (Fig. 40) moderately oblong, 1.06-1.08 times as long as broad, disc with moderately pronounced and rather extensive median elevation; lateral contours behind eyes smoothly and weakly curving towards posterior constriction in dorsal view, posterior angles obsolete; punctation very dense, rather coarse, weakly confluent in places, and distinctly umbilicate; interstices forming narrow ridges, without microsculpture. Eyes approximately one-third as long as distance from posterior margin of eye to posterior constriction in dorsal view, or slightly longer. Antenna approximately $1.9 \mathrm{~mm}$ long, rather long in relation to body size.

Pronotum (Fig. 40) rather weakly oblong, 1.15-1.18 times as long as broad and $0.90-0.95$ times as broad as head; punctation dense and much coarser than that of head; midline with more or less pronounced impunctate glossy elevation in posterior half; lateral portions with uneven surface, with irregular longitudinal glossy callosities; interstices without microsculpture and glossy.

Elytra (Fig. 40) approximately 0.53 times as long as pronotum; humeral angles obsolete; dorsal surface more or less extensively depressed or impressed anteriorly; punctation defined and rather coarse, but distinctly less coarse than that of pronotum; interstices without microsculpture and glossy. Hind wings completely reduced. Metatarsomere I much shorter than the combined length of II-V.

Abdomen approximately 1.25 times as broad as elytra; punctation coarse and dense on tergites III-V, less dense and finer on tergite VI, and rather sparse and fine on tergites VII and VIII; interstices without microreticula- 
tion; posterior margin of tergite VII without palisade fringe; posterior margin of tergite VIII strongly convex (Fig. 41).

$\sigma^{\star}$ : sternite VII (Fig. 42) strongly transverse, approximately 1.55 times as broad as long, with shallow postero-median impression with sparse long and dark setae obliquely directed postero-mediad, posterior margin with conspicuously large concavity, this concavity with a pair of dense clusters of long black setae in the middle and with a sparser row of very long black setae laterally; sternite VIII (Fig. 43) indistinctly transverse, posterior excision conspicuously narrow and deep, approximately half as deep as length of sternite; aedeagus (Figs 44-45) approximately $0.95 \mathrm{~mm}$ long; ventral process of oblong triangular shape and apically acute, subapically with a small ventral tooth (best visible in lateral view); dorso-lateral apophyses long and straight, extending somewhat beyond apex of ventral process, and apically moderately dilated.

Comparative notes: Nazeris semifissus is well-characterized by the conspicuous modifications of the male sternite VII, the remarkably deep and narrow posterior incision of the male sternite VIII, and by the morphology of the aedeagus. Similar apomorphies were not found in any other species recorded from Yunnan and adjacent regions (Guangxi and Guizhou provinces; North Vietnam).

Distribution and natural history: The type locality is situated in the Dawei Shan Virgin Forest Park near Pingbian in southeastern Yunnan (Map 3) and identical to that of $N$. discissus. The specimens were sifted from leaf litter in a primary subtropical broad-leaved forest at an altitude of $2100 \mathrm{~m}$.

\section{Nazeris fibulatus sp. $\mathrm{n}$ (Figs 46-51, Map 3)}

Type material: Holotype $0^{*}$ : "CHINA [3] - Yunnan, E Kunming, $24^{\circ} 55^{\prime} 43^{\prime \prime} \mathrm{N}, 103^{\circ} 05^{\prime} 22^{\prime \prime} \mathrm{E}, 2110 \mathrm{~m}$, Xiaobailong Forest Park, 10.VIII.2014, V. Assing / Holotypus o Nazeris fibulatus sp. n., det. V. Assing 2014" (cAss). Paratypes: $3 \sigma^{\top} \sigma^{\top}$ [ 1 teneral]: same data as holotype (cAss).

Etymology: The specific epithet is an adjective derived from the Latin noun fibula (clip, clamp) and alludes to the shape of the dorso-lateral apophyses.

Description: Species of moderate size; body length 5.8-6.7 mm; length of forebody 3.1-3.3 mm. Coloration: body black; legs and antennae yellowish.

Head (Fig. 46) moderately oblong, 1.06-1.09 times as long as broad; lateral contours behind eyes smoothly curving towards posterior constriction in dorsal view, posterior angles obsolete; punctation very dense, moderately coarse, rather shallow, partly confluent, and distinctly umbilicate; interstices forming narrow ridges, without microsculpture. Eyes less than one-third as long as distance from poste- rior margin of eye to posterior constriction in dorsal view. Antenna approximately $1.9 \mathrm{~mm}$ long.

Pronotum (Fig. 46) slender, approximately 1.25 times as long as broad and 0.85 times as broad as head; punctation very dense and much coarser than that of head; midline posteriorly with short and narrow impunctate glossy elevation; lateral portions without distinct impressions or elevations; interstices without microsculpture and glossy. Elytra (Fig. 46) approximately 0.55 times as long as pronotum; humeral angles obsolete; punctation approximately as coarse and as dense as that of pronotum; interstices without microsculpture and glossy. Hind wings completely reduced. Metatarsomere I elongated, nearly as long as the combined length of II-V.

Abdomen approximately 1.2 times as broad as elytra; punctation coarse and dense on tergites III-V, slightly less dense on tergite VI, slightly less coarse and somewhat less dense on tergite VII; interstices without microreticulation; posterior margin of tergite VII with narrow rudiment of a palisade fringe; posterior margin of tergite VIII strongly convex.

$o^{*}$ : sternite VII (Fig. 47) moderately transverse, approximately 1.35 times as broad as long, without conspicuous modifications; sternite VIII (Fig. 48) transverse, approximately 1.2 times as broad as long, posterior excision $\mathrm{V}$-shaped and approximately one-fourth as deep as length of sternite; aedeagus (Figs 49-50) 1.0-1.1 mm long; ventral process laterally compressed, with very narrow ventral surface (Fig. 51), and apically obliquely truncate in lateral view; dorso-lateral apophyses strongly sclerotized, long, extending slightly beyond apex of ventral process, and of distinctive bisinuate shape.

Comparative notes: Nazeris fibulatus is distinguished from its congeners particularly by the morphology of the aedeagus (shape of dorso-lateral apophyses; long and ventrally sharp ventral process). The general morphology of the aedeagus is similar to that of some species of the $N$. cangicus group (see Assing 2013) such as N. pungens Assing, 2013 (Xue Shan near Lincang), N. lanuginosus Assing, 2013 (Laobie Shan), N. peniculatus Assing, 2013 (environs of Dali), N. barbatus Assing, 2013 (Wuliang Shan), N. subdentatus Assing, 2013 (Gaoligong Shan), and N. curvus Assing, 2013 (Gaoligong Shan).

Distribution and natural history: The type locality is situated to the east of Kunming in eastern Yunnan (Map 3). The specimens were sifted from pine and leaf litter in a secondary pine forest with broad-leaved undergrowth at an altitude of $2110 \mathrm{~m}$. One of the paratypes is teneral.

\section{Nazeris bulbosus sp. $\mathrm{n}$.}

(Figs 52-59, Map 3)

Type material: Holotype $0^{\star}:$ "CHINA [4] - Yunnan, NE Kunming, 2509'07"N, 10253'46"E, 2280 m, sec. pine for. with alder, 11.VIII.2014, V. Assing / Holotypus $0^{*}$ Nazeris bulbosus sp. n., det. V. Assing 2014" (cAss). 


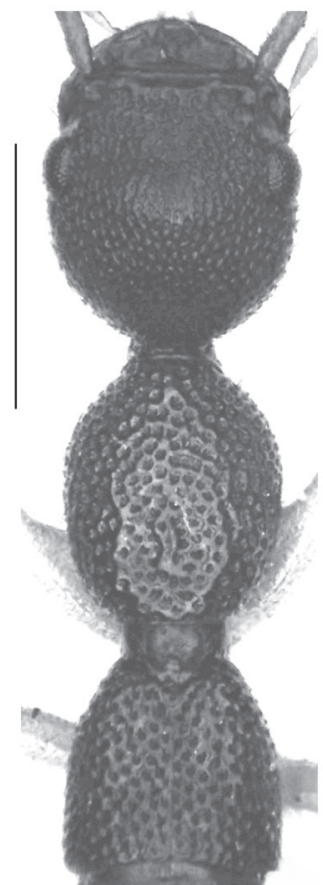

46

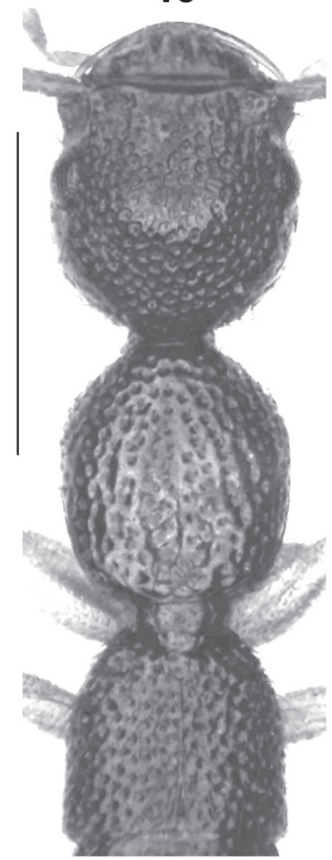

52

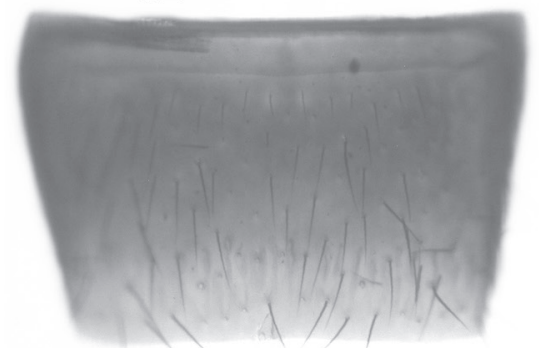

53

55

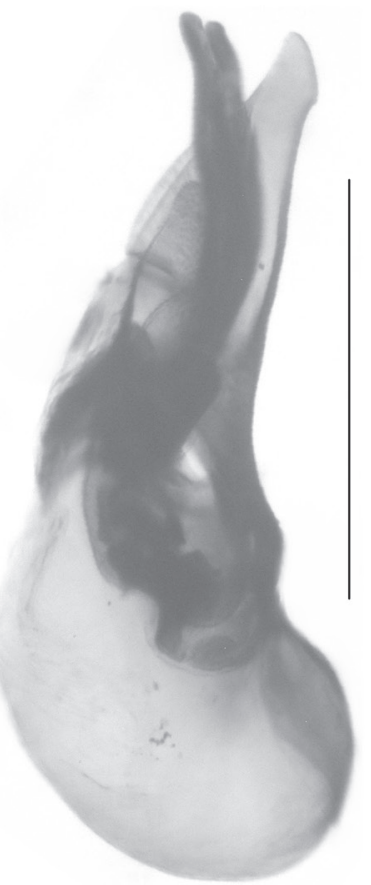

49

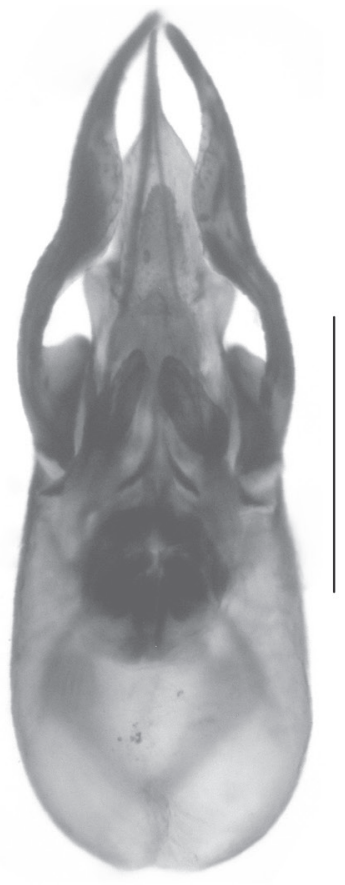

50

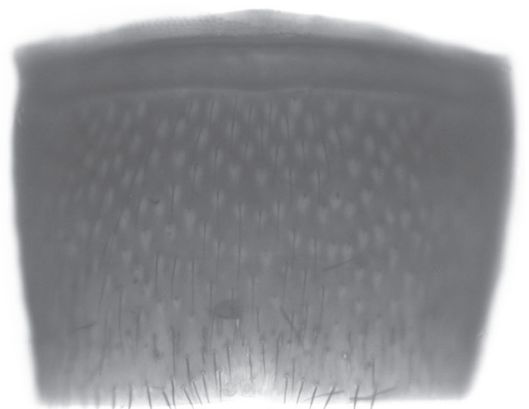

47

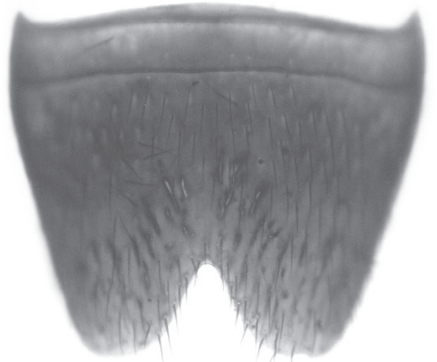

48
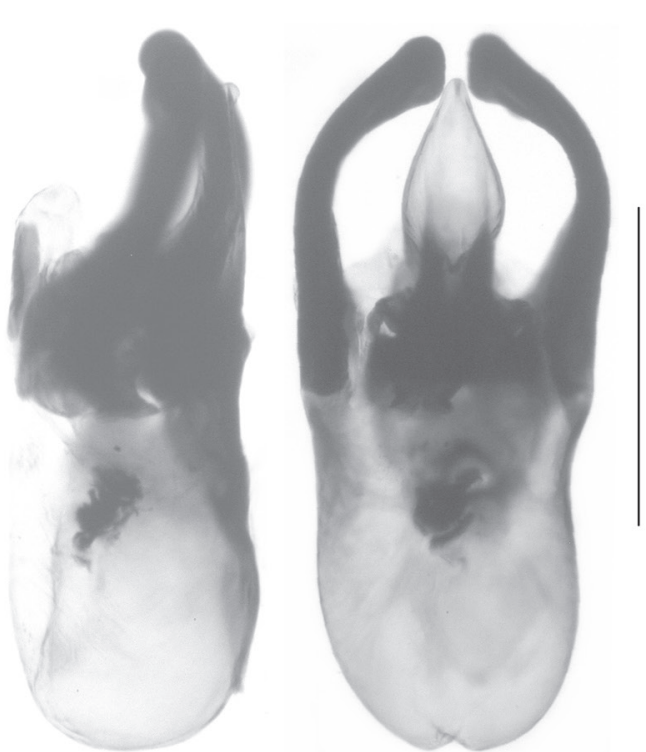

56

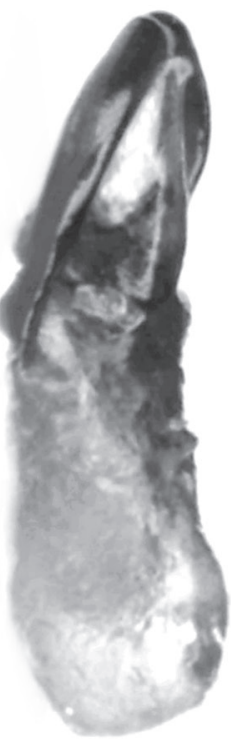

57

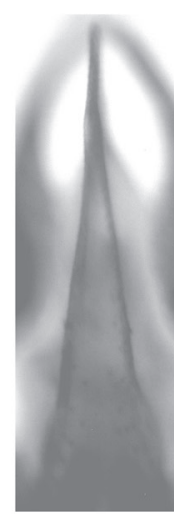

51

Figs 46-58: Nazeris fibulatus sp. n. (46-51) and N. bulbosus sp. n. (52-58): forebody (46, 52); male sternite VII (47, 53); male sternite VIII $(48,54)$; aedeagus in lateral and in ventral view $(49-50,55-56)$; ventral process of aedeagus in ventral view (51); aedeagus in lateral and in ventral view in dry preparation (57-58). Scale bars: 46, 52: $1.0 \mathrm{~mm}$; 47-50, 53-58: $0.5 \mathrm{~mm}$; $51: 0.2 \mathrm{~mm}$. 


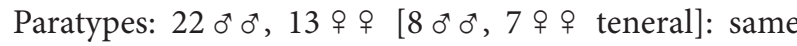
data as holotype (cAss, MNHUB); $13 o^{\star} o^{x}, 10$ 우 우 [2 $0^{\star} o^{*}$, 1 i teneral]: same data, but leg. M. Schülke (cSch); $4 o^{\star} \sigma^{*}, 4$ 우 우 [2 o $^{*}$ teneral]: “CHINA [5] - Yunnan, NE Kunming, $25^{\circ} 08^{\prime} 40^{\prime \prime N}, 102^{\circ} 53^{\prime} 48^{\prime \prime E}, 2290$ m, mixed forest, sifted, 11.VIII.2014, V. Assing" (cAss, MNHUB); $3 \sigma^{\star} \sigma^{\star}, 4$ 우 우 [3 우 ㅇ teneral]: same data, but leg. M. Schülke (cSch); 4 o $0^{\star}, 5$ 우 우 [1 teneral]: "CHINA

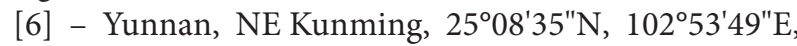
$2320 \mathrm{~m}$, mixed forest, sifted, 13.VIII.2014, V. Assing" (cAss, MNHUB); 3 đo o, 3 i ㅇ [1 9 teneral]: same data, but leg. M. Schülke (cSch).

Etymology: The specific epithet is an adjective derived from the Latin noun bulbus (onion, garlic) and alludes to the shape of ventral process of the aedeagus in ventral view, which somewhat resembles an elongated onion.

Description: Species of relatively small size; body length 4.2-5.5 mm; length of forebody $2.4-2.7 \mathrm{~mm}$. Coloration: body blackish-brown to blackish, with the head often dark reddish-brown; legs and antennae yellowish.

Head (Fig. 52) weakly to moderately oblong, 1.021.09 times as long as broad; lateral contours behind eyes relatively strongly convex in dorsal view; punctation very dense and rather coarse, not confluent, and distinctly umbilicate; interstices forming narrow ridges, without microsculpture. Eyes mostly slightly more than one-third as long as distance from posterior margin of eye to posterior constriction in dorsal view, rarely shorter. Antenna 1.4-1.5 mm long.

Pronotum (Fig. 52) relatively weakly oblong, approximately $1.10-1.15$ times as long as broad and 0.90-0.95 times as broad as head; punctation very dense, deeper and coarser than that of head; midline posteriorly with or without short and very narrow impunctate glossy band; lateral portions regular punctation, without distinct impressions or elevations; interstices without microsculpture and glossy.

Elytra (Fig. 52) approximately 0.55 times as long as pronotum; humeral angles obsolete; punctation very dense, less coarse than that of pronotum; interstices without microsculpture and glossy. Hind wings completely reduced. Metatarsomere I elongated, nearly as long as the combined length of II-V.

Abdomen approximately 1.2 times as broad as elytra; punctation coarse and dense on tergite III, gradually becoming less dense towards tergite $\mathrm{V}$, distinctly finer and sparser on tergites VI-VIII; interstices without microreticulation; posterior margin of tergite VII without palisade fringe; posterior margin of tergite VIII moderately convex.

$\sigma^{\top}$ : sternite VII (Fig. 53) moderately transverse, approximately 1.55 times as broad as long, with sparse pubescence, without conspicuous modifications; sternite VIII (Fig. 54) transverse, 1.10-1.15 times as broad as long, posterior excision rather small and $\mathrm{V}$-shaped and approximately one-fifth as deep as length of ster- nite; aedeagus (Figs 55-58) 0.80-0.87 mm long; ventral process short, shaped like an oblong onion in ventral view, laterally not compressed; dorso-lateral apophyses stout, strongly curved (ventral view), strongly sclerotized, apically dilated and vertically truncate, and moderately long, extending slightly beyond apex of ventral process.

Comparative notes: Based on the external and the male primary and secondary sexual characters, N. bulbosus is closely allied to N. zhangi from the Yuan Shan to the West of Kunming, from which it differs by larger body size (N. zhangi: body length according to the original description 4.1-4.4 mm; length of forebody 2.3-2.4 mm) the darker coloration of the forebody ( $N$. zhangi: according to the original description "reddish brown to reddish black"), the paler antennomere I ( $N$. zhangi: according to the original description yellowish-brown), and particularly by the apically stouter and vertically truncate dorso-lateral apophyses of the aedeagus (N. zhangi: dorso-lateral apophyses apically distinctly oblique with acute internal angle). For illustrations of N. zhangi see WATANABE \& XiAO (1993).

Distribution and natural history: The known distribution of N. bulbosus is confined to three geographically close localities to the northeast of Kunming (Map 3). The specimens were sifted from litter in a secondary pine forest, a mixed deciduous forest with scattered pine trees, and a mixed forest with alder, oak and pine at altitudes of 2280-2320 m. Numerous paratypes are teneral.

\section{Nazeris clavilobatus sp. $\mathrm{n}$.}

(Figs 59-67, Map 3)

Type material: Holotype $o^{*}$ : “CHINA [7] - Yunnan, mts W Dongchuan, $2620 \mathrm{~m}, 26^{\circ} 06^{\prime} 08^{\prime \prime} \mathrm{N}, 102^{\circ} 54^{\prime} 46^{\prime \prime E}$, pine for., 14.VIII.2014, V. Assing / Holotypus ơ Nazeris clavilobatus sp. n., det. V. Assing 2014" (cAss).

Paratypes: $4 \sigma^{\star} o^{\star}, 1$ 우 : same data as holotype (cAss); 2 우 우 same data, but leg. M. Schülke (cSch).

Etymology: The specific epithet (Latin, adjective) alludes to the distinctly club-shaped dorso-lateral apophyses of the aedeagus.

Description: Species of relatively small size; body length $4.5-5.3 \mathrm{~mm}$; length of forebody $2.4-2.7 \mathrm{~mm}$. Forebody as in Fig. 59. Coloration: head and elytra dark reddishbrown to blackish-brown; pronotum and abdomen blackish-brown to blackish, with the abdominal segments IX-X and the posterior margins of segments VII and VIII pale-reddish; legs and antennae yellowish. Abdominal tergite VIII and posterior portion of tergite VII with shallow microsculpture; posterior margin of tergite VIII weakly convex (Fig. 60). Other external characters as in N. bulbosus.

$\sigma^{*}$ : sternite VII (Fig. 61) moderately transverse, approximately 1.5 times as broad as long, with sparse pubescence, 


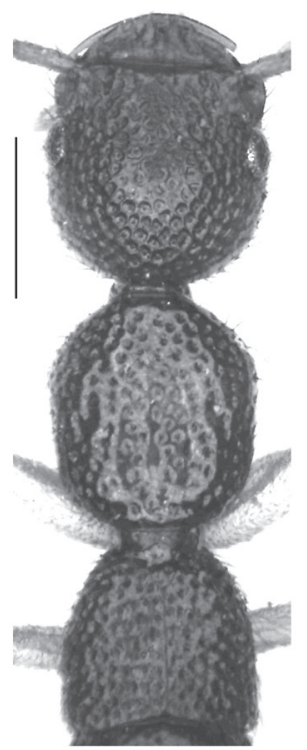

59

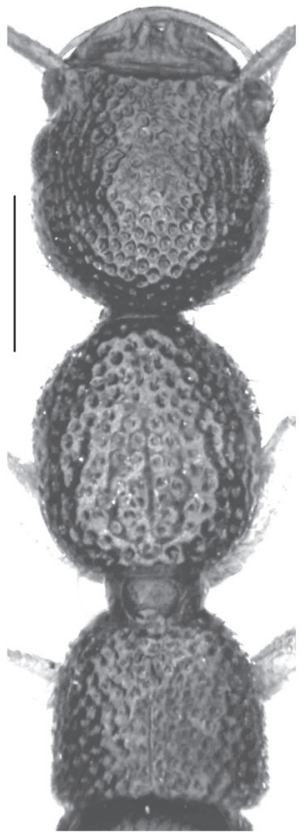

68

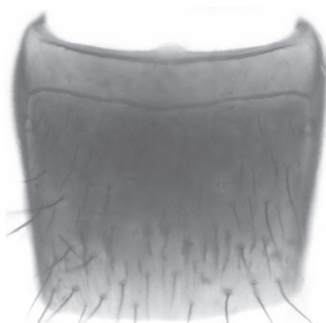

60

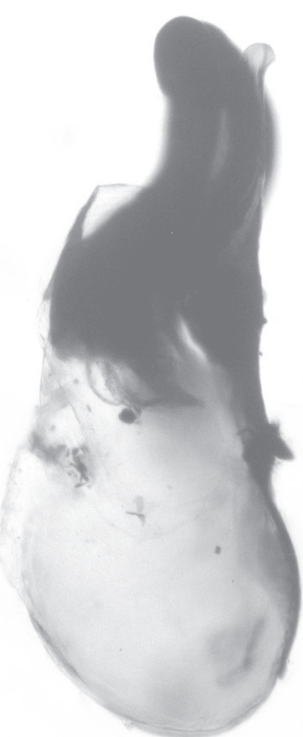

63

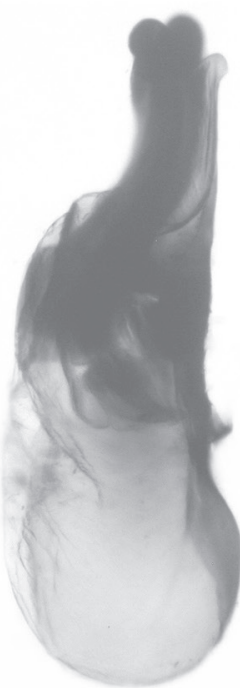

72

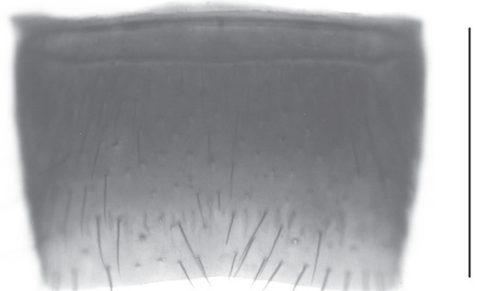

61

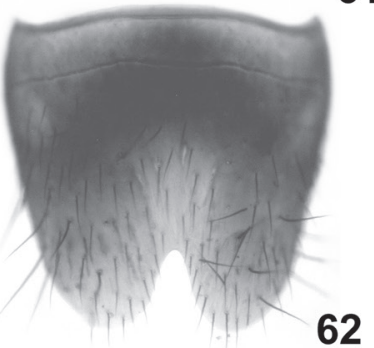

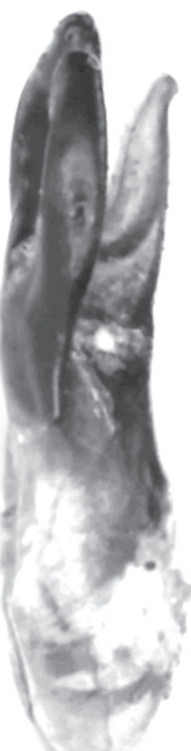

64

65

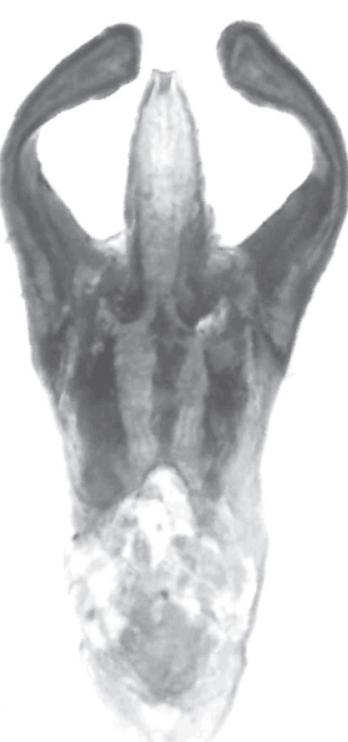

66

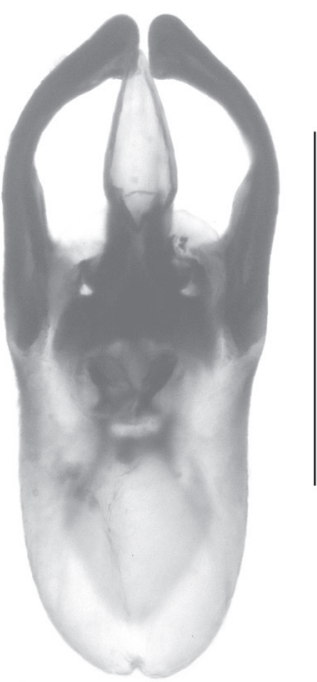

73

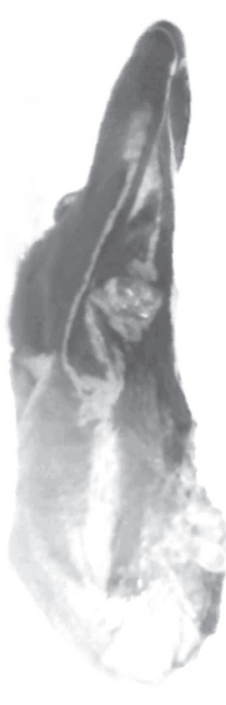

74

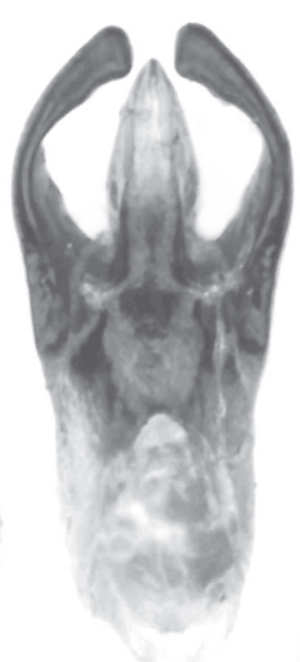

75

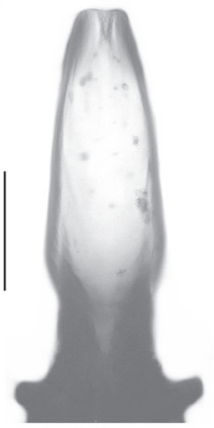

67

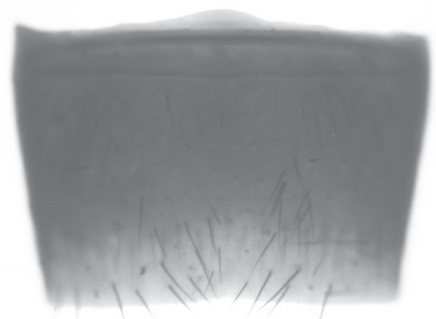

69
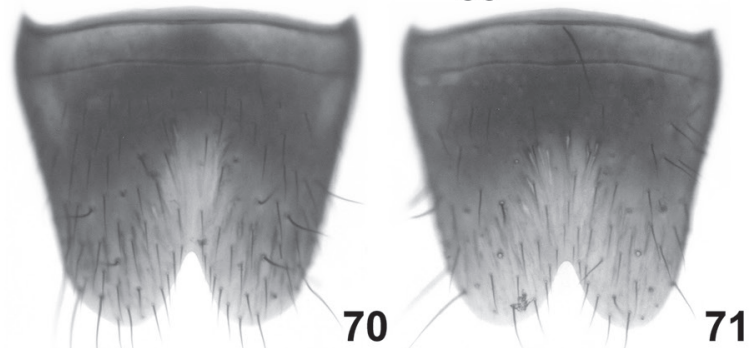

Figs 59-75: Nazeris clavilobatus sp. n. (59-67) and N. conicus sp. n. (68-75): forebody (59, 68); tergite VIII (60); male sternite VII $(61,69)$; male sternite VIII $(62,70-71)$; aedeagus in lateral and in ventral view $(63-64,72-73)$; aedeagus in lateral and in ventral view in dry preparation (65-66, 74-75); ventral process of aedeagus in ventral view (67). Scale bars: 59, 68: $1.0 \mathrm{~mm} ; 60-66,69-75$ : $0.5 \mathrm{~mm}$; 67: $0.1 \mathrm{~mm}$. 
without evident modifications; sternite VIII (Fig. 62) approximately as broad as long, posterior excision relatively narrow and approximately one-fourth as deep as length of sternite; aedeagus (Figs 63-66) approximately 0.96-1.0 mm long; ventral process moderately short and rather slender, lateral margins only weakly converging apically in ventral view (Fig. 67); dorso-lateral apophyses stout, strongly curved (ventral view), strongly sclerotized, apically clubbed, and moderately long, extending beyond apex of ventral process.

Comparative notes: As can be inferred from the similar external and male sexual characters, N. clavilobatus is allied to $N$. zhangi and N. bulbosus. It is distinguished from both by the differently shaped ventral process and dorso-lateral apophyses of the aedeagus, from the latter additionally by the reddish apex of the abdomen, the presence of the microsculpture on tergite VII and VIII, the deeper and narrower posterior excision of the differently shaped male sternite VIII (not transverse), and by the longer aedeagus. For characters distinguishing $N$. clavilobatus from the highly similar $N$. conicus see the following section.

Distribution and natural history: The type locality is situated near the Sedan Snow Mountain Scenic Resort to the west of Dongchuan in northeastern Yunnan (Map 3), not far from the type locality of $N$. brevilobatus. The specimens were sifted from litter, moss, and the roots of herbs in a secondary terraced pine forest at an altitude of $2620 \mathrm{~m}$.

\section{Nazeris conicus sp. $\mathrm{n}$.}

(Figs 68-75, Map 3)

Type material: Holotype $\sigma^{*}$ : "CHINA [9] - Yunnan, mt. W Xundian, $2300 \mathrm{~m}$, mixed for., $25^{\circ} 34^{\prime} 58^{\prime \prime} \mathrm{N}, 103^{\circ} 08^{\prime} 42^{\prime \prime E}$, sifted, 15.VIII.2014, V. Assing / Holotypus o $0^{*}$ Nazeris conicus sp. n., det. V. Assing 2014" (cAss).

Paratypes: $5 \sigma^{\star \top} o^{\star}, 7$ 우 $ᄋ$ [1 $\sigma^{\star}, 4$ 우 우 teneral]: same data as holotype (cAss, MNHUB); 1 : same data, but

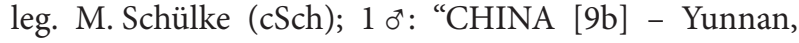
mt. W Xundian, $2300 \mathrm{~m}$, mixed for., $25^{\circ} 34^{\prime} 58^{\prime \prime} \mathrm{N}$, $103^{\circ} 08^{\prime} 42^{\prime \prime E}$, sifted, 16.VIII.2014, V. Assing” (cAss).

Etymology: The specific epithet (Latin, adjective) alludes to the conical shape of the ventral process (ventral view).

Description: Species of relatively small size; body length $4.5-5.6 \mathrm{~mm}$; length of forebody $2.5-2.8 \mathrm{~mm}$. Forebody as in Fig. 68. Coloration: body blackish, with the head sometimes slightly paler (dark-brown to blackish-brown) and with the abdominal segments IX-X dark-brown and the posterior margins of segments VII and VIII reddish-brown. Abdominal tergites VII and VIII without microsculpture; posterior margin of tergite VIII weakly convex. Other external characters as in N. clavilobatus and N. bulbosus.
$0^{7}$ : $\quad$ sternite VII (Fig. 69) moderately transverse, 1.50-1.55 times as broad as long, with sparse pubescence, without evident modifications; sternite VIII (Figs 70-71) usually weakly transverse, 1.00-1.08 times as broad as long, posterior excision $\mathrm{V}$-shaped and $0.21-0.23$ times as deep as length of sternite; aedeagus (Figs 72-75) 0.90-0.93 mm long; ventral process rather slender in ventral view, laterally not compressed; dorsolateral apophyses stout, strongly curved (ventral view), strongly sclerotized, and moderately long, extending beyond apex of ventral process.

Comparative notes: Regarding the morphology of the aedeagus, N. conicus is highly similar to N. clavilobatus, from which it differs by slightly larger average size, darker coloration, the absence of microsculpture on the abdominal tergites VII and VIII, the anteriorly more acute posterior excision of the male sternite VIII, and by the smaller aedeagus (despite larger average body size) with a conically shaped (i.e., medially broader and apically more distinctly tapering) ventral process (ventral view). The observed differences are not very pronounced, but apparently constant. However, material from the region between the type localities of $N$. conicus and $N$. clavilobatus, which are separated by approximately $65 \mathrm{~km}$, would be needed to confirm the hypothesis that they represent distinct species.

Distribution and natural history: The type locality is situated in a mountain to the west of Xundian, approximately $70 \mathrm{~km}$ to the northeast of Kunming, in eastern Yunnan (Map 3). The specimens were sifted from litter (partly with twigs) and the roots of herbs in a mixed forest with alder, pine, and shrub undergrowth at an altitude of $2300 \mathrm{~m}$. Several paratypes are teneral.

\subsection{Unnamed species}

\section{Nazeris sp. 1}

Material examined: China: 5 우, Yunnan, mountain SE Gejiu, $23^{\circ} 18^{\prime} 27^{\prime \prime} \mathrm{N}, 103^{\circ} 11^{\prime} 41^{\prime \prime E}, 2400 \mathrm{~m}$, graveyard with pine, litter sifted, 20.VIII.2014, leg. Assing \& Schülke (cAss, cSch).

Comment: The above females most likely represent an undescribed species. They were collected together with the type specimens of $N$. constrictus. Based on external characters (size, punctation, shape of tergite VIII) this species may be allied to $N$. zhangi and its close relatives.

\section{Nazeris sp. 2}

Material examined: China: 1 i [teneral], Yunnan, mountains S Jianshui, $23^{\circ} 25^{\prime} 18^{\prime \prime} \mathrm{N}, 102^{\circ} 50^{\prime} 53^{\prime} \mathrm{E}, 1810 \mathrm{~m}$, forest margin, leaf litter sifted, 22.VIII.2014 (cSch). 
Comment: Based on external characters, the above female most likely represents an undescribed species of the $N$. brevilobatus group.

\section{Acknowledgements}

I am indebted to Michael Schülke (Berlin) for the opportunity to study his Nazeris material from eastern Yunnan. Benedikt Feldmann (Münster) proof-read the manuscript.

\section{References}

Assing, V. 2013: On the Nazeris fauna of China II. New species and records from Zhejiang, Sichuan, and Yunnan (Coleoptera: Staphylinidae: Paederinae). Bonn Zoological Bulletin 62 (2): 125-170.

Assing, V. 2014a: A revision of Nazeris. IV. New species from China, Taiwan, and Thailand, and additional records (Coleoptera: Staphylinidae: Paederinae). Stuttgarter Beiträge zur Naturkunde A, Neue Serie 7: 11-32.
Assing, V. 2014b: A revision of the Nazeris fauna of the Himalaya (Coleoptera: Staphylinidae: Paederinae). Stuttgarter Beiträge zur Naturkunde A, Neue Serie 7: 65-130.

Assing, V. in press: A revision of Pronomaea ERICHson. II. A new species from China and additional records (Coleoptera: Staphylinidae: Aleocharinae). - Linzer Biologische Beiträge 46 (2) (2014).

Watanabe, Y. 1996: A new species of the genus Nazeris (Coleoptera, Staphylinidae) from Yunnan Province, Southwest China. - Elytra 21 (1): 129-133.

Watanabe, Y. \& XiaO, N. N. 1993: A new Nazeris (Coleoptera, Staphylinidae) from Northern Vietnam. - Species Diversity 1: 1-5. 